\title{
Selectivity of Neuromodulatory Projections from the Basal Forebrain and Locus Ceruleus to Primary Sensory Cortices
}

\author{
Jae-Hyun Kim, ${ }^{1}$ A-Hyun Jung, ${ }^{1}$ Daun Jeong, ${ }^{1}$ Ilsong Choi, ${ }^{1}$ Kwansoo Kim, ${ }^{1}$ Soowon Shin, ${ }^{2}$ Sung June Kim, ${ }^{2}$ \\ and ${ }^{-S e u n g}$-Hee Lee ${ }^{1}$ \\ ${ }^{1}$ Department of Biological Sciences, Korea Advanced Institute of Science and Technology, Daejeon 34141, Korea, and ${ }^{2}$ Department of Electrical and \\ Computer Engineering, Seoul National University, Seoul 08826, Korea
}

Acetylcholine and noradrenaline are major neuromodulators that affect sensory processing in the cortex. Modality-specific sensory information is processed in defined areas of the cortex, but it is unclear whether cholinergic neurons in the basal forebrain (BF) and noradrenergic neurons in the locus ceruleus (LC) project to and modulate these areas in a sensory modality-selective manner. Here, we mapped BF and LC projections to different sensory cortices of the mouse using dual retrograde tracing. We found that while the innervation of cholinergic neurons into sensory cortices is predominantly modality specific, the projections of noradrenergic neurons diverge onto multiple sensory cortices. Consistent with this anatomy, optogenetic activation of cholinergic neurons in BF subnuclei induces modality-selective desynchronization in specific sensory cortices, whereas activation of noradrenergic LC neurons induces broad desynchronization throughout multiple sensory cortices. Thus, we demonstrate a clear distinction in the organization and function of cholinergic BF and noradrenergic LC projections into primary sensory cortices: cholinergic BF neurons are highly selective in their projections and modulation of specific sensory cortices, whereas noradrenergic LC neurons broadly innervate and modulate multiple sensory cortices.

Key words: basal forebrain; cholinergic; locus ceruleus; neuromodulation; noradrenergic; sensory cortex

Significance Statement

Neuromodulatory inputs from the basal forebrain (BF) and locus ceruleus (LC) are widespread in the mammalian cerebral cortex and are known to play important roles in attention and arousal, but little is known about the selectivity of their cortical projections. Using a dual retrobead tracing technique along with optogenetic stimulation, we have identified anatomic and functional differences in the way cholinergic BF neurons and noradrenergic LC neurons project into primary sensory cortices. While BF projections are highly selective to individual sensory cortices, LC projections diverge into multiple sensory cortices. To our knowledge, this is the first definitive proof that BF and LC projections to primary sensory cortices show both anatomic and functional differences in selectivity for modulating cortical activity.

\section{Introduction}

Sensory modality-specific information is processed in specialized sensory cortices in defined regions of the mammalian neocortex

Received Dec. 2, 2015; revised March 30, 2016; accepted April 1, 2016.

Author contributions: J.-H.K. and S.-H.L. designed research; J.-H.K., A.-H.J., D.J., and S.-H.L. performed research; S.S. and S.J.K. contributed unpublished reagents/analytic tools; A.-H.J., I.C., and K.K. analyzed data; J.-H.K. and S.-H.L. wrote the paper.

This work was supported by grants to S.-H.L. from the Korean government through the National Research Foundation of Korea funded by the Ministry of Science, ICT \& Future Planning (MSIP; 2015048055 and NRF2014R1A1A3054603), the Korea Health Technology R\&D Project through the Korea Health Industry Development Institute funded by the Ministry of Health \& Welfare (HI14C2437), and the MSIP as Global Frontier Project (CISS2012M3A6A6054204). It was also supported by a National Alliance for Research on Schizophrenia and Depression Young Investigator Grant funded by the Brain \& Behavior Research Foundation and an End Run project supported by the Korea Advanced Institute of Science and Technology (KAIST; N01150685). A.-H.J. was supported by a KAIST Undergraduate Research Program fellowship (N01130909) and K.K. was supported by a TJ Park Science Fellowship. We thank Dr. Yang Dan and Dr. Siyu Zhang for helpful discussions and Dr. Jinhyung Kim for advice on data analysis.
(Felleman and Van Essen, 1991). The physiological properties of these sensory cortices are dynamically modulated by subcortical neuromodulatory centers (Harris and Thiele, 2011; Lee and Dan, 2012). The cholinergic neurons of the basal forebrain (BF) and noradrenergic neurons of the locus ceruleus (LC), for example, send long-range axonal projections into sensory cortices and modulate their properties by releasing acetylcholine and noradrenaline, respectively (Sarter and Parikh, 2005; Sara, 2009; Picciotto et al., 2012; Sara and Bouret, 2012). Both of these neuromodulators are important for cortical state switching, especially for entry into the aroused and attentive states. Direct

The authors declare no competing financial interests.

Correspondence should be addressed to Seung-Hee Lee at the above address. E-mail: shlee1@kaist.ac.kr. DOl:10.1523/JNEUROSCI.4333-15.2016

Copyright $\odot 2016$ the authors $\quad 0270-6474 / 16 / 365314-14 \$ 15.00 / 0$ 
Table 1. Summary of all samples analyzed for the dual retrograde tracing

\begin{tabular}{|c|c|c|c|c|c|c|c|c|c|c|}
\hline \multirow{2}{*}{$\begin{array}{l}\text { Injection } \\
\text { sites }\end{array}$} & \multirow[b]{2}{*}{ Case } & \multicolumn{4}{|l|}{$\mathrm{BF}$} & \multirow[b]{2}{*}{ Case } & \multicolumn{4}{|l|}{$\mathrm{LC}$} \\
\hline & & V1 & $\mathrm{A} 1$ & S1 & Dual & & V1 & $\mathrm{A} 1$ & S1 & Dual \\
\hline \multirow[t]{4}{*}{ V1-A1 } & $\# 1^{*}$ & 65 (4) & $30(4)$ & - & $4(2)$ & $\# 1^{*}$ & $175(8)$ & $85(7)$ & - & $62(7)$ \\
\hline & $\# 7$ & $64(3)$ & 91 (3) & - & $4(1)$ & $\# 3^{*}$ & $132(13)$ & $43(16)$ & - & $93(5)$ \\
\hline & $\# 8^{*}$ & $107(4)$ & 128 (1) & - & $10(0)$ & $\# 4^{*}$ & 91 (36) & $184(23)$ & - & $47(6)$ \\
\hline & $\# 9^{*}$ & 74 (1) & 65 (2) & - & $3(1)$ & $\# 5$ & $186(9)$ & $190(2)$ & - & $109(0)$ \\
\hline Mean \pm SEM & & $\begin{array}{l}74.4 \pm 6.8 \\
\quad(5.9 \pm 1.9)\end{array}$ & $\begin{array}{l}87.9 \pm 12.4 \\
(7.6 \pm 2.5)\end{array}$ & - & $\begin{array}{l}5.3 \pm 1.7 \\
\quad(1.1 \pm 0.4)\end{array}$ & & $\begin{array}{l}141.7 \pm 16.5 \\
\quad(12.3 \pm 4.9)\end{array}$ & $\begin{array}{r}140.3 \pm 25.1 \\
\quad(9.3 \pm 3.4)\end{array}$ & - & $\begin{array}{l}81.8 \pm 14.9 \\
\quad(3.7 \pm 1.1)\end{array}$ \\
\hline \multirow[t]{4}{*}{ V1-S1 } & $\# 12$ & 49 (8) & - & $78(10)$ & $6(2)$ & $\# 12$ & $117(6)$ & - & $130(2)$ & $98(0)$ \\
\hline & $\# 13^{*}$ & $62(7)$ & - & $119(6)$ & $0(5)$ & $\# 13^{*}$ & $281(63)$ & - & 79 (21) & $110(10)$ \\
\hline & $\# 14^{*}$ & $61(7)$ & - & 57 (3) & $4(0)$ & $\# 14^{*}$ & $128(9)$ & - & $146(10)$ & 77 (3) \\
\hline & $\# 15^{*}$ & $86(6)$ & - & $86(5)$ & $6(0)$ & $\# 16^{*}$ & $124(10)$ & - & $142(12)$ & $83(5)$ \\
\hline \multirow{5}{*}{$\mathrm{A} 1-\mathrm{S} 1$} & $\# 19^{*}$ & - & $52(1)$ & 61 (2) & $17(0)$ & $\# 19^{*}$ & - & $282(26)$ & $187(15)$ & $143(7)$ \\
\hline & $\# 20^{*}$ & - & $39(0)$ & $102(3)$ & $4(1)$ & $\# 20^{*}$ & - & $23(1)$ & $225(8)$ & $73(1)$ \\
\hline & $\# 21$ & - & $82(6)$ & $119(8)$ & $3(0)$ & $\# 21$ & - & $127(6)$ & $73(7)$ & $47(1)$ \\
\hline & \#22 & - & $121(17)$ & 64 (4) & 21 (1) & $\# 22$ & - & $121(2)$ & $120(0)$ & $85(0)$ \\
\hline & $\# 23^{*}$ & - & 65 (6) & 65 (4) & $4(1)$ & $\# 23^{*}$ & - & $192(25)$ & 85 (16) & $98(5)$ \\
\hline Mean \pm SEM & & - & $\begin{array}{l}71.8 \pm 11.6 \\
(7.3 \pm 2.8)\end{array}$ & $\begin{array}{l}75.3 \pm 11.9 \\
(3.8 \pm 0.9)\end{array}$ & $\begin{array}{l}9.5 \pm 3.1 \\
\quad(0.5 \pm 0.2)\end{array}$ & & - & $\begin{array}{l}169.8 \pm 40.7 \\
\quad(13.2 \pm 4.7)\end{array}$ & $\begin{array}{l}134.3 \pm 24.3 \\
(9.0 \pm 2.4)\end{array}$ & $\begin{array}{l}91.2 \pm 13.1 \\
\quad(2.5 \pm 1.1)\end{array}$ \\
\hline Total & & $\begin{array}{l}67.4 \pm 5.8 \\
(6.7 \pm 1.2)\end{array}$ & $\begin{array}{l}80.5 \pm 9.1 \\
\quad(7.5 \pm 1.9)\end{array}$ & $\begin{array}{l}77.5 \pm 8.7 \\
\quad(8.0 \pm 1.1)\end{array}$ & $\begin{array}{l}6.2 \pm 1.3 \\
\quad(1.1 \pm 0.3)\end{array}$ & & $\begin{array}{l}144.7 \pm 16.8 \\
\quad(15.3 \pm 5.5)\end{array}$ & $\begin{array}{l}155.1 \pm 23.2 \\
\quad(11.3 \pm 2.8)\end{array}$ & $\begin{array}{r}129.5 \pm 13.8 \\
\quad(9.8 \pm 1.8)\end{array}$ & $\begin{array}{l}86.8 \pm 4.8 \\
\quad(3.5 \pm 0.5)\end{array}$ \\
\hline
\end{tabular}

For V1-A1 and V1-S1 cases, asterisks $\left(^{*}\right)$ indicate the cases in which we injected red retrobeads into V1. For A1-S1 cases, asterisks indicate the cases in which we injected red retrobeads into A1. The numbers of ChAT + and TH + cells are indicated outside the parentheses, while the numbers of $\mathrm{ChAT}$ - and $\mathrm{TH}$ - cells are indicated inside the parentheses.

activation of noradrenergic LC neurons switches the brains of behaving animals from sleep to wakefulness (Carter et al., 2010). Activation of cholinergic BF neurons induces the cortical desynchronization (Goard and Dan, 2009; Pinto et al., 2013; Eggermann et al., 2014) that characterizes attention and arousal (Metherate et al., 1992; Fries et al., 2001; Poulet and Petersen, 2008; Harris and Thiele, 2011). The attention state enhances the ability of the cortex to process information by guiding its perceptual focus onto specific sensory contents (Corbetta and Shulman, 2002). Selective attention to a given sensory stimulus alters the activity of the specific region of the sensory cortex specialized for responding to that stimulus (Steinmetz et al., 2000; Fries et al., 2001). Both cholinergic and noradrenergic modulations are critical for the attentional modulation of cortical activity (AstonJones et al., 1994; Herrero et al., 2008). Previous studies have shown that these modulators produce different states in the same sensory cortex (Constantinople and Bruno, 2011; CastroAlamancos and Gulati, 2014). It is still unclear, however, whether cholinergic and noradrenergic projections are discrete enough to mediate the distinct modulation of specific areas in the sensory cortex.

The BF is a large structure that encompasses multiple cholinergic nuclei (Schwaber et al., 1987). BF neurons innervating the cortex are mostly found in the horizontal diagonal band of Broca (HDB) and the nucleus basalis of Meynert (NB; Luiten et al., 1987; Bloem et al., 2014), although the functional distinction between these two nuclei remains unclear. Glutamatergic and GABAergic neurons intermingling with the cholinergic BF neurons (Brashear et al., 1986; Gritti et al., 2006) also project to the cortex (Gritti et al., 1997; Henny and Jones, 2008). The LC, in contrast, is a small brainstem nucleus comprising $<1500$ neurons in mice (Sturrock and Rao, 1985). Although most LC neurons are noradrenergic, some are GABAergic or serotonergic neurons (Iijima, 1989, 1993). Topographic distinction of the BF and LC neurons has been proposed (Bigl et al., 1982; Loughlin et al., 1982; Saper, 1984; Bloem et al., 2014), but the selectivity and topography of the BF and LC neurons projecting to distinct sensory cortices have not yet been fully defined.

To better understand these neuromodulatory projections, we attempt here to clarify the anatomy of the cholinergic and noradrenergic projections to different primary sensory cortices and the selectivity with which they modulate discrete sensory cortical areas in the mouse brain. We performed retrograde tracing from the primary visual (V1), auditory (A1), and somatosensory (S1) cortices. We found that while cholinergic BF projections are highly selective and modality specific, noradrenergic LC neurons broadly innervate multiple sensory cortices. Furthermore, optogenetic activation of cholinergic neurons in the HDB or NB desynchronizes specific sensory cortices, but activation of noradrenergic LC neurons broadly desynchronizes multiple sensory cortices. Our results thus demonstrate that cholinergic BF and noradrenergic LC neurons employ two distinct modulatory paradigms in the sensory cortex: modality-selective versus multisensory modulation.

\section{Materials and Methods}

Animal subjects. The Korea Advanced Institute of Science and Technology Institutional Animal Care and Use Committee (IACUC-13-145) approved all experimental procedures. We used wild-type mice of both sexes [postnatal day (P) 60-P150; 43 males and 25 females] for the dual-tracing experiments. To selectively express channelrhodopsin-2 (ChR2) in the cholinergic or noradrenergic neurons, we crossed ChAT-Cre mice (B6;129S6Chat $<\operatorname{tml}$ (cre)Lowl $>/$ J, Jackson Laboratories) or TH-Cre mice (B6; Cg$\mathrm{Tg}$ (Th-cre)1Tmd/J; Jackson Laboratories) with loxP-flanked ChR2-EYFP 
A
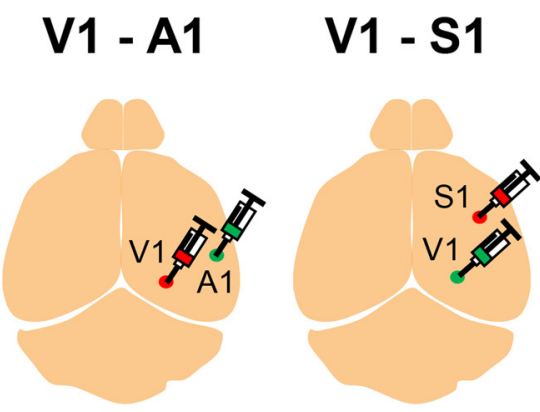

B

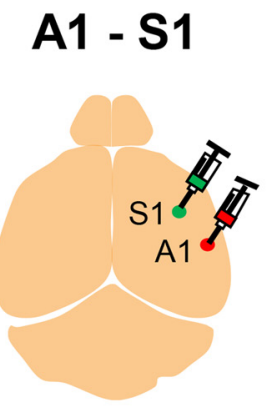

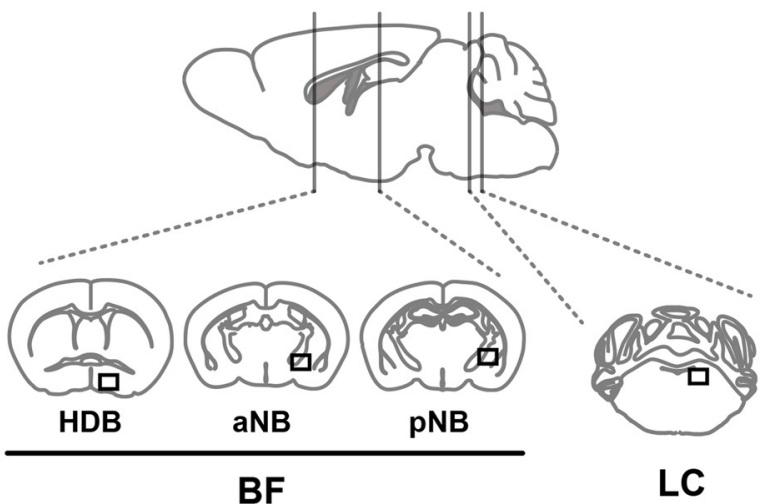

C

Thalamic Nuclei
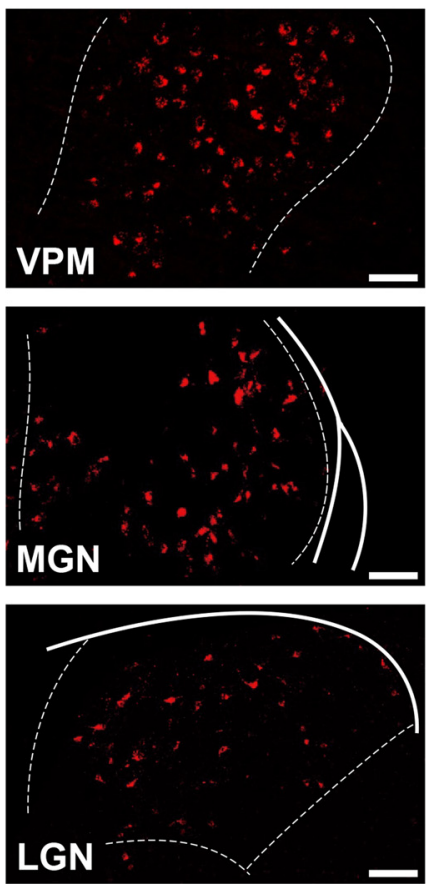

Thalamocortical Connections

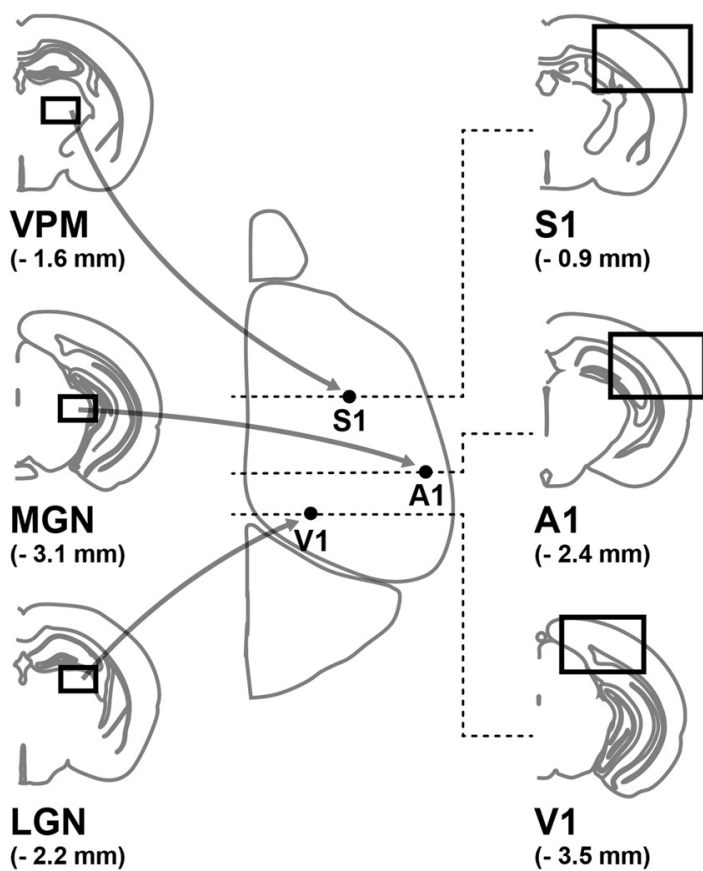

Injection Sites
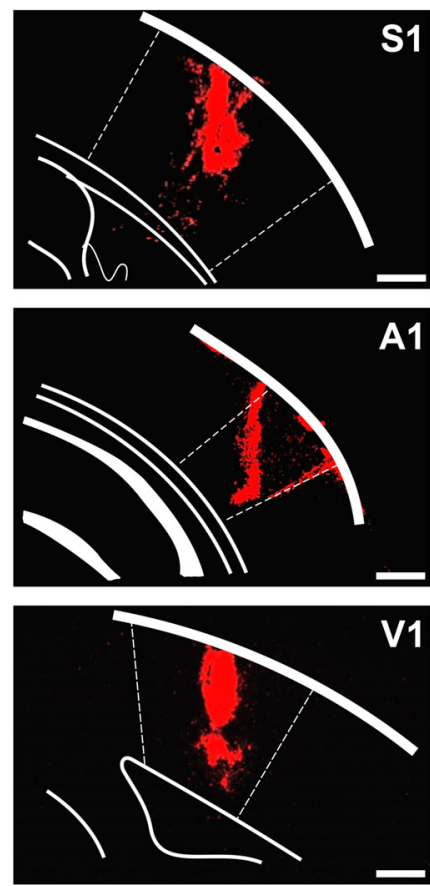

Figure 1. Dual retrograde tracing of sensory cortices. $A$, Schematic of the retrobead injections. V1-A1, V1-S1, and A1-S1 indicate the primary sensory cortices into which each of the three groups of samples received green and red retrobead injections. $\boldsymbol{B}$, Traced and imaged regions of the BF and LC. Bottom, Representative coronal sections within the regions serially sectioned. The vertical lines indicate the boundaries of the imaged areas and the black squares indicate the area analyzed within each section. $\boldsymbol{C}$, Traced thalamic regions from each sensory cortex. Left, Fluorescence images of the ventral posteromedial nucleus (VPM), medial geniculate nucleus (MGN), and lateral geniculate nucleus (LGN) showing labeled neurons traced from S1, A1, and V1, respectively. Scale bars, 200 $\mu \mathrm{m}$. Center, Schematic illustrating the relevant thalamocortical connections. Arrows indicate axonal projections. Dotted lines indicate coronal sections at the injection sites. Right, Fluorescence images of the S1, A1, and V1 injection sites. Scale bars, $500 \mu \mathrm{m}$. White lines indicate the boundaries of thalamic nuclei and the injection sites. The numbers indicate the position of sections relative to the bregma (in millimeters).

reporter mice (Ai32, B6;129S-Gt(ROSA)26Sortm32(CAG-COP4*H134R/ EYFP)Hze/J; Jackson Laboratories), respectively. Then, we used mice expressing both Cre and ChR2-EYFP (ChAT-ChR2-EYFP or TH-ChR2-EYFP) for electrophysiological recordings.

Dual retrograde tracing. After anesthetizing mice with 1.5\% isoflurane in oxygen, we restrained them in a stereotaxic apparatus (David Kopf Instruments). We used a temperature control system with a heating pad (CWE) to maintain their body temperature at $37^{\circ} \mathrm{C}$ throughout surgery. After achieving full anesthesia, we cut the skin on the head and cleaned the connective tissue on top of the craniotomy. We made a small craniotomy $0.5 \mathrm{~mm}$ in diameter above injection sites targeting V1-A1, V1-S1, and A1-S1 (See Table 1 for details regarding animal groups and a summary of each group's tracing results). The targeted injection sites were all made on the right hemisphere as follows: $\mathrm{V} 1$ (bregma, $-3.50 \mathrm{~mm}$; lateral,
$1.80 \mathrm{~mm}$; depth, $0.50 \mathrm{~mm}$ ), A1 (bregma. $-2.40 \mathrm{~mm}$; lateral, $4.20 \mathrm{~mm}$; depth, $0.80 \mathrm{~mm}$ ), and $\mathrm{S} 1$ (bregma, $-0.90 \mathrm{~mm}$; lateral, $3.00 \mathrm{~mm}$; depth, $0.60 \mathrm{~mm}$ ). We performed the dual-tracing experiments by microinjecting green and red retrobeads (LumaFluor) into each pair of targeted cortical areas. To do so, we loaded the retrobeads into a sharp glass micropipette with the Nanoliter 2010 injector (WPI) attached to the stereotaxic arms. Five minutes after inserting the pipette, we injected 13.8 $\mathrm{nl}$ pulses of retrobeads at intervals of $30 \mathrm{~s}$ until reaching a total injection volume of 200-300 $\mathrm{nl}$ per injection site. After loading the beads and withdrawing the glass pipette, we resealed the cut skin with Vetbond (3M).

Histology. Between 3 and $5 \mathrm{~d}$ after retrobead injection, we deeply anesthetized the mice with isoflurane and perfused them with PBS, pH 7.4, and $4 \%$ paraformaldehyde (w/v in PBS). We isolated and postfixed the 
A

B

$$
\text { V1 - A1 }
$$

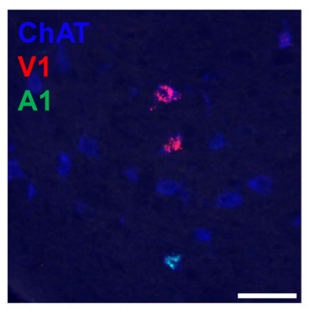

\section{$0.14 \mathrm{~mm}$}
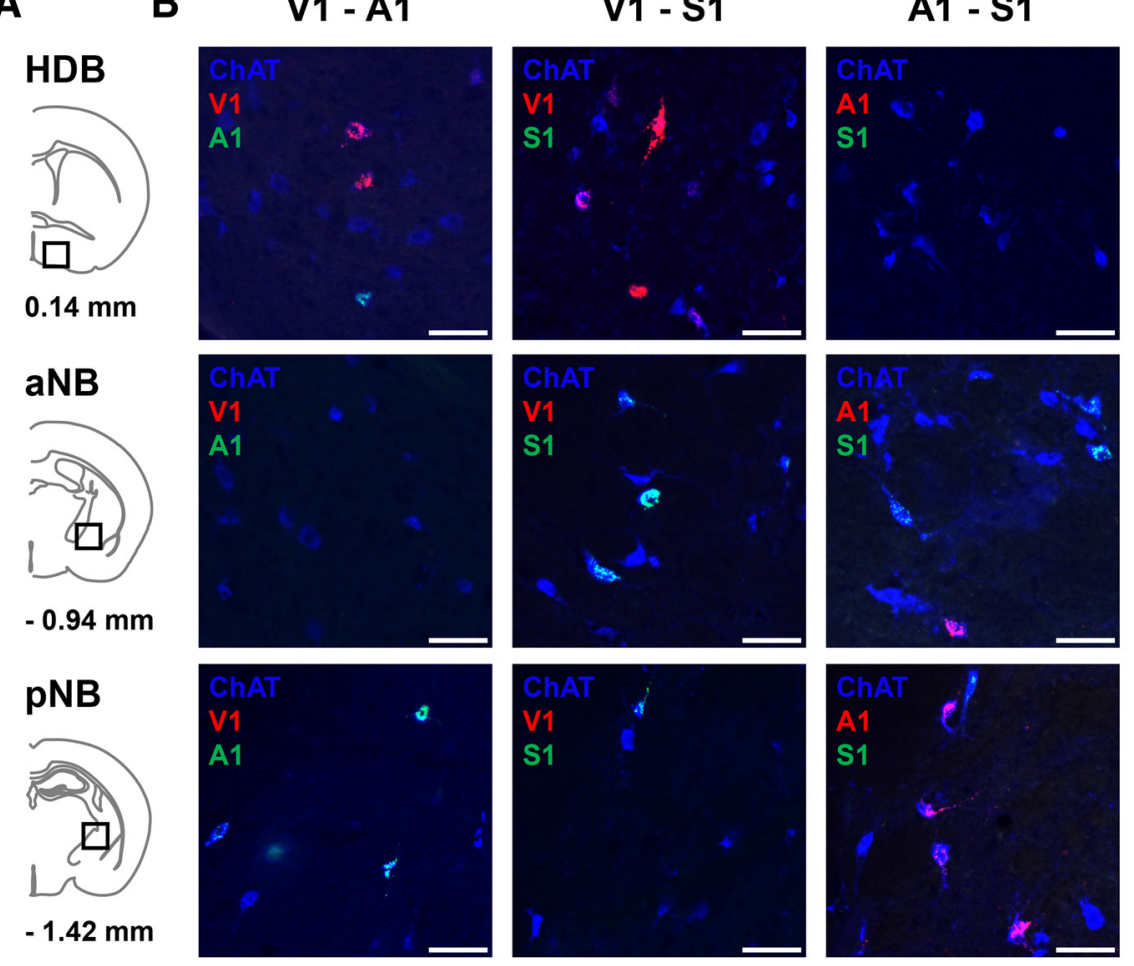

C V1 - A1
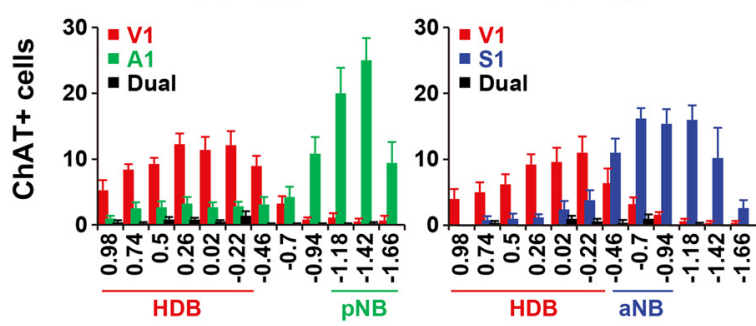

V1 - S1

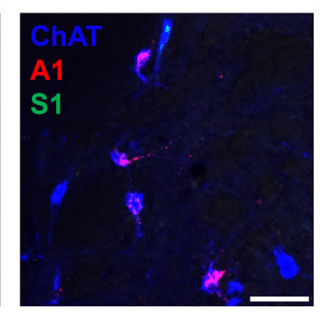

A1 - S1
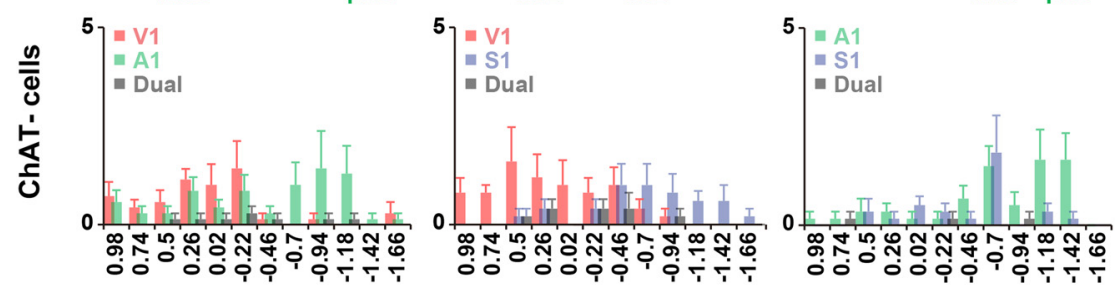

D

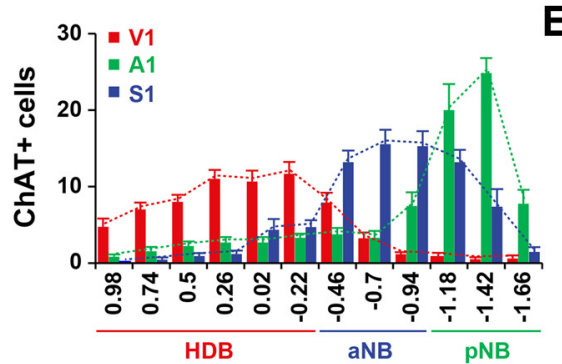

E

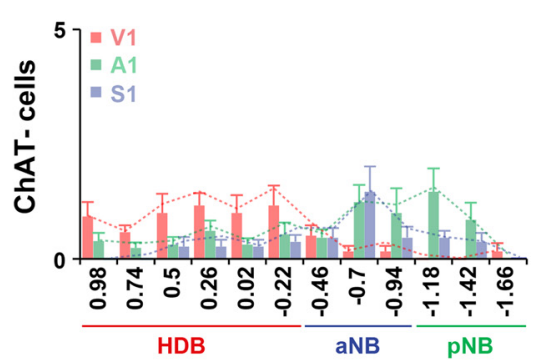

AP position from bregma $(\mathrm{mm})$

Figure 2. Cholinergic $B F$ neurons show selective projections to the sensory cortex. $A$, Schematic of brain sections including the $\mathrm{HDB}$, aNB, and pNB BF areas (anterior to posterior). Black squares indicate the imaged BF areas. $B$, Fluorescence images of ChAT+ $B F$ neurons labeled with green and red retrobeads in the three injection groups (V1-A1, V1-S1, A1-S1). Top, Labeled cells in the HDB; middle, aNB; bottom, pNB; red, red retrobeads; green, green retrobeads; blue, ChAT; scale bars, $50 \mu \mathrm{m}$. C, Top, Topographic localization of retrobead-labeled ChAT + cells along the anterior-to-posterior BF in the three groups (V1-A1, $n=7 ; \mathrm{V} 1-\mathrm{S1}, n=$ $5 ; A 1-S 1, n=6 ; n$ represents the number of animals). Bars indicate the number of retrobead-labeled cholinergic (ChAT +$)$ neurons (mean \pm SEM). Red, green, and blue bars indicate neurons projecting to V1, A1, and S1, respectively. Black bars indicate neurons labeled with both green and red retrobeads, meaning they project to two different sensory cortices. The horizontal lines brain samples for $4-12 \mathrm{~h}$ before incubating them in filtered $30 \%$ sucrose in PBS for $1-2 \mathrm{~d}$ at $4^{\circ} \mathrm{C}$. After the brain samples sank completely in the $30 \%$ sucrose solution, we embedded them in optimal cutting temperature compound and froze them using dry ice and ethanol. We then cut the frozen brains into $15 \mu \mathrm{m}$ (BF and LC areas for immunohistochemistry, collecting one of every four slices) or $30 \mu \mathrm{m}$ (injection sites and thalamic areas, collecting one of every three slices) coronal sections using a cryostat (Leica) and attached them serially on the slide glass. To confirm the success of each injection, we washed the brain slices three times with 0.1 $\mathrm{M} P B$, mounted them in fluorescent mounting medium (DAKO), and checked them from the injection sites and from the thalamus under a fluorescence microscope (BX41, Olympus). All subsequent immunostaining was performed after confirming retrograde labeling of the thalamic areas that specifically project into each targeted sensory cortex. For immunostaining, we washed the brain slices of the BF and LC three times and permeabilized them with $0.1 \%$ Triton X-100 in $0.1 \mathrm{M}$ PB. After incubating them in blocking solution (2\% normal donkey serum in $0.1 \mathrm{M} \mathrm{PB}$ ) for $2 \mathrm{~h}$ at room temperature (RT), we incubated them with primary antibodies [goat anti-ChAT (1:500; Millipore) and rabbit anti-TH (1:1000; Abcam)] for $2 \mathrm{~d}$ at $4^{\circ} \mathrm{C}$. Last, we washed the sections three times and incubated them with secondary antibodies for $2 \mathrm{~h}$ at RT [Alexa Fluor 647 donkey anti-goat IgG (for ChAT staining; Invitrogen); Alexa Fluor 647 donkey anti-rabbit IgG (for $\mathrm{TH}$ staining; Jackson Immunoresearch); 1:500 dilution in $0.1 \mathrm{M} \mathrm{PB}$ ] before mounting them in fluorescence mounting medium with (i.e., in Vectashield) or without 4',6-diamidino-2phenylindole (DAPI; i.e., in Dako fluorescence mounting medium).

Imaging, cell counting, and topographic analysis. We obtained fluorescent images of immunostained brain slices using the fluorescence microscope and scanned brain section series under a scanning microscope (Zeiss AxioSCAN). We imaged slices from $+0.98 \mathrm{~mm}$ to $-1.66 \mathrm{~mm}$ (covering the $\mathrm{BF}$ ) and from $-5.14 \mathrm{~mm}$ to $-5.98 \mathrm{~mm}$ (covering the LC) to the bregma and counted the retrobead-labeled neurons appearing there. We confirmed the anterior-to-posterior location of these coronal brain slices by matching the scanned images to the brain atlas (Franklin and Paxinos, 2008). We obtained the detailed representative images using a confocal microscope (Zeiss LSM 780). We manually counted the retrobead-labeled

below the graphs indicate the anterior-to-posterior extent of the HDB, aNB, pNB, in the BF. Bottom, Same as the top, but for noncholinergic (ChAT-) neurons. D, E, Combined distribution of retrobead-labeled ChAT $+(\boldsymbol{D})$ and $\mathrm{ChAT}-(\boldsymbol{E})$ neurons in the BF. Data from the three different groups in $\mathbf{A}-\mathbf{C}$ are combined based on the target sensory cortices. Bars indicate the number of cells labeled with a single type of retrobead (mean \pm SEM). Dotted lines indicate the total number of retrobead-labeled neurons. 
A

B

V1 - A1

V1 - S1

A1 - S1
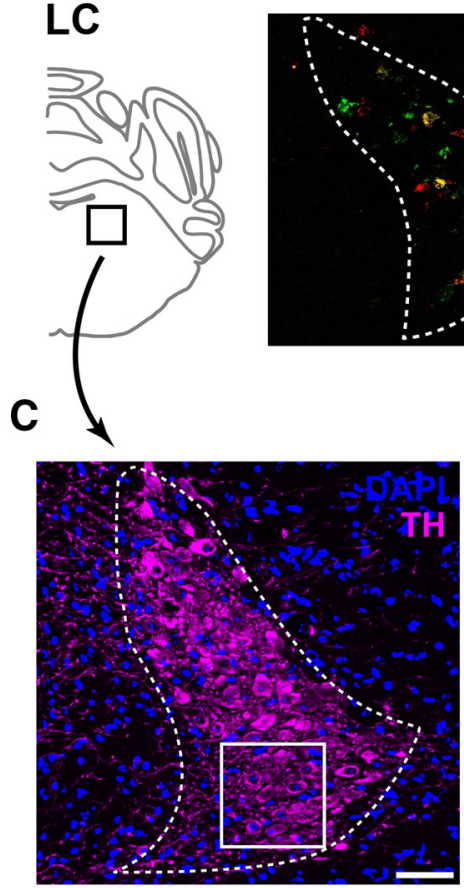

E
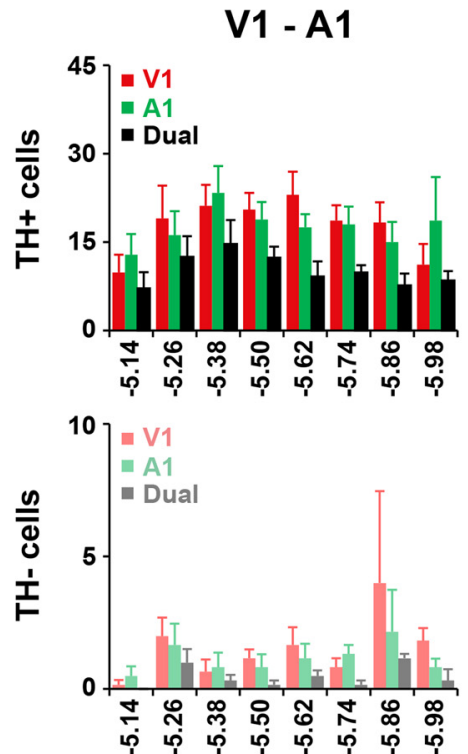

$\mathbf{F}$

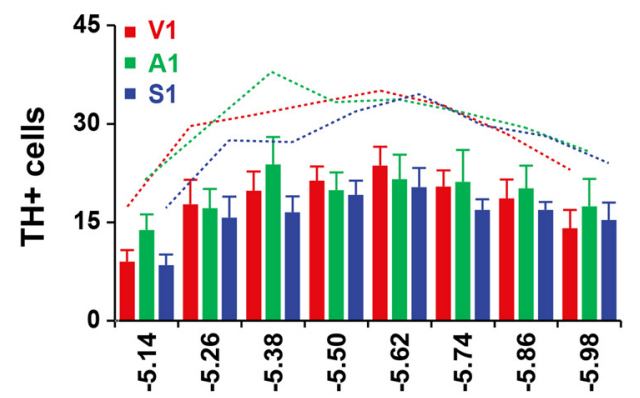

V1 - S1
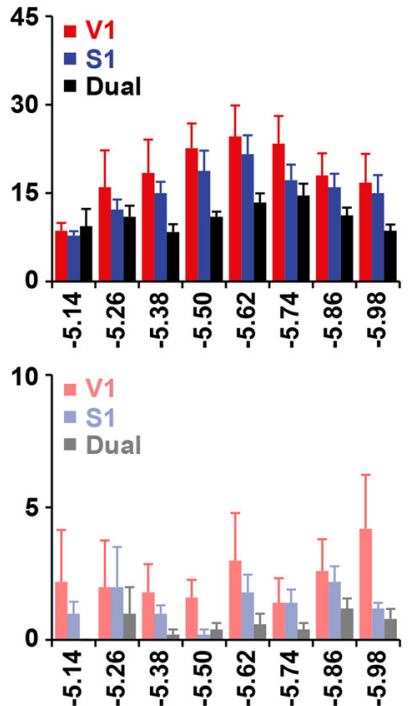

G

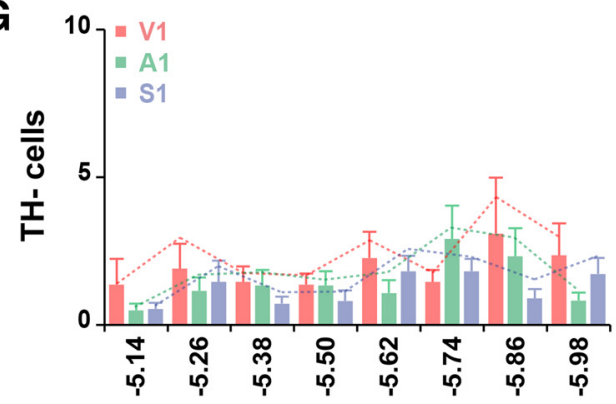

\section{AP position from bregma $(\mathrm{mm})$}

Figure 3. Noradrenergic $\mathrm{LC}$ neurons show diverging projection to multiple sensory cortices. $A$, Schematic of the $\mathrm{LC}$ in the brainstem. The black square indicates the imaged area, which includes the LC. $B$, Representative images of the $L C$ from each of the three injection groups (V1-A1, V1-S1, A1-S1). Dotted lines indicate the LC boundary as defined by TH immunostaining. Red, Red retrobeads; green, green retrobeads. Scale bars, $50 \mu \mathrm{m}$. C, Left, Representative image of TH and DAPI staining in the LC from the V1-A1 injection group (green, (Figure legend continues.) 
and immunostained cells. For dorsal-ventral (DV) and medial-lateral (ML) topography, we chose representative sections containing the most labeled neurons and analyzed the position and number of BF neurons within $3 \times 3 \mathrm{~mm}^{2}$ regions-of-interest in seven representative coronal sections and the position and number of LC neurons within $1 \times 1 \mathrm{~mm}^{2}$ regions-of-interest in two representative coronal sections. For bar graphs in Figure 4, we binned the length of DV and ML axes into 15 units $(0.2$ $\mathrm{mm}$ for BF, $0.067 \mathrm{~mm}$ for LC) and quantified the average number of traced neurons in each bin along the axes. We calculated the selectivity index of the BF and LC projecting neurons by normalizing the differences in cell number of unimodal and bimodal projections by the total number of projecting cells.

Local field potential recordings and optogenetic stimulation. We inserted $200 \mu \mathrm{m}$ optic fibers (Thorlabs) connected to ferrules into the HDB (bregma, $+0.03 \mathrm{~mm}$; lateral, $1.30 \mathrm{~mm}$; depth, $5.00 \mathrm{~mm}$ ), posterior $\mathrm{NB}$ (pNB; bregma, $-1.40 \mathrm{~mm}$; lateral, $2.50 \mathrm{~mm}$; depth, $3.30 \mathrm{~mm}$ ), or LC (bregma, $-5.40 \mathrm{~mm}$; lateral, $0.90 \mathrm{~mm}$; depth, $2.30 \mathrm{~mm}$ ) of mice anesthetized with $1.5 \%$ isoflurane. Then, we attached custom-designed head plates to the skull with small screws (Small Parts) and dental cement (Lang Dental). After 1-2 d of recovery, we anesthetized the mice with urethane (2 g per kg body weight, i.p.) and restrained them in a customdesigned head-fix apparatus. We maintained the body temperature of the mice at $37^{\circ} \mathrm{C}$ throughout the recordings. After inserting a custom-made liquid crystal polymer (LCP) probe (Lee et al., 2012) into the brain using a microdrive manipulator (Siskiyou), we recorded local field potentials (LFPs) using the RHD 2000-Series Amplifier Evaluation System (Intan Technologies), filtering at $0.5-350 \mathrm{~Hz}$ with a $20 \mathrm{kHz}$ sampling rate. We used a blue laser ( $473 \mathrm{~nm}$; Shanghai Laser \& Optics Century) for the optogenetic stimulation during LFP recordings in the sensory cortices. We used 2, 4, 6, and $8 \mathrm{~mW}$ laser outputs as measured at the tip of the optic fiber. We controlled the laser using a stimulus generator (A-M Systems), giving $5 \mathrm{~s}$ light stimuli with $20 \mathrm{~s}$ intertrial intervals for a total recording time of 10 min per session. This meant we were able to perform 23-24 trials per session. We recorded the laser output events simultaneously with neural activity using the RHD-2000 Series Amplifier Evaluation System (Intan Technologies). We used a single-shank LCP probe to perform each series of recordings in a single mouse brain moving from V1 to A1 to S1 while delivering identical light stimuli through the implanted optic fiber. We used a double-shank LCP probe inserted into both V1 and A1 to simultaneously monitor LFP changes in both sensory cortices during optical stimulation. After completing the recordings, we killed the mice and confirmed proper optic fiber targeting by imaging the HDB, $\mathrm{pNB}$, or LC. To confirm specific expression of ChR2 in the cholinergic and noradrenergic neurons from ChAT-ChR2-EYFP and TH-ChR2EYFP mice, respectively, we also imaged the HDB, pNB, and LC with immunohistochemistry (ChAT staining for ChAT-ChR2-EYFP mice, TH staining for TH-ChR2-EYFP mice). In total, we used 12 ChAT-ChR2EYFP mice for HDB activation, 10 ChAT-ChR2-EYFP mice for $\mathrm{pNB}$ activation, and 8 TH-ChR2-EYFP mice for LC activation.

Recording data analysis. We analyzed our recording data as previously described (Goard and Dan, 2009; Pinto et al., 2013). We used short-term Fourier transform spectrogram analysis to quantify LFP power and cus-

\footnotetext{
(Figure legend continued.) $\quad \mathrm{A1}$; red, V1). Scale bar, $50 \mu \mathrm{m}$. Right, Enlarged view of the area inside the white square in the left image. Blue, DAPI; magenta, TH; scale bar, $10 \mu \mathrm{m}$. D, Representative images of the six types of retrobead-labeled $L C$ neurons. The images in the third row indicate the cell in the right white box from $C$. The color of DAPI was changed from blue to cyan to minimize confusion. Scale bars, $10 \mu \mathrm{m}$. $\boldsymbol{E}$, Top, Topographic localization of retrobead-labeled $\mathrm{TH}+$ cells along the anterior-to-posterior $\mathrm{LC}$ in the three groups (V1-A1, $n=6 ; \mathrm{V} 1-\mathrm{S} 1, n=5$; $A 1-S 1, n=6 ; n$ represents the number of animals). Bars indicate the number of noradrenergic $(\mathrm{TH}+)$ retrobead-labeled neurons (mean $\pm \mathrm{SEM}$ ). Red, green, and blue bars indicate neurons projecting to $\mathrm{V1}, \mathrm{A1}$, and $\mathrm{S1}$, respectively. Black bars indicate neurons labeled with both green and red retrobeads. Bottom, Same as the top, but for TH - cells. F, G, Combined distribution of retrobead-labeled $\mathrm{TH}+(\boldsymbol{F})$ and $\mathrm{TH}-(\boldsymbol{G})$ neurons in the $\mathrm{LC}$. Data from the three different groups in $\boldsymbol{A}-\boldsymbol{C}$ are combined based on their target sensory cortices. Bars indicate the number of cells labeled with a single type of retrobead (mean \pm SEM). Dotted lines indicate the total number of retrobead-labeled neurons.
}

tom Matlab code to compute the normalized, averaged spectral power and the desynchronization ratio. For the spectral analysis, we analyzed frequencies of $0.5-100 \mathrm{~Hz}$ within a $1 \mathrm{~s}$ sliding window with $50 \mathrm{~ms}$ steps and normalized each frequency power by the baseline before laser onset. To measure the desynchronization ratio time course, we divided the average power of the high frequencies $(30-80 \mathrm{~Hz})$ by that of the low frequencies ( $1-10 \mathrm{~Hz} ; 1 \mathrm{~s}$ sliding window with $50 \mathrm{~ms}$ steps). For the mean desynchronization ratio analysis, we excluded $2 \mathrm{~s}$ worth of data surrounding the laser onset to remove the artifact generated by laser stimulation. We calculated statistical significance for this ratio using the Student's $t$ test.

\section{Results}

\section{Dual retrograde tracing from primary sensory cortices}

To map projections from the BF and LC to primary sensory cortices, we injected green and red retrobeads into two of three major primary sensory cortices (i.e., V1, A1, and S1) on the right hemisphere of the mouse brain (Fig. 1A). We set two criteria for successful retrograde tracing with retrobeads: injection accuracy and positive retrograde labeling. First, we required brain samples to show restricted retrobead injection within the targeted primary sensory cortices without excessive leakage on the pia of other cortical areas or deep into the white matter below the cortex (Fig. $1 C$, right). Second, we required retrobeads in each sensory cortex to label presynaptic neurons in the corresponding sensory thalamic nucleus (i.e., the lateral geniculate nucleus for V1, the medial geniculate nucleus for A1, and the ventral posteromedial nucleus for S1; Fig. 1C, left; López-Bendito and Molnár, 2003). We applied these restrictions sequentially, such that we looked for retrobeads in thalamic neurons only after an injection was deemed accurate. For brain samples that satisfied these criteria, we mapped the neurons projecting to sensory cortices along the anterior-posterior (AP) axis of the BF and LC that were cut into serial coronal sections (Fig. $1 B$ ). We identified cholinergic and noradrenergic neurons in these slices by immunostaining with antibodies against ChAT (Woolf et al., 1983; Rye et al., 1984) and TH (Steindler and Trosko, 1989; Iijima, 1993), respectively.

\section{Topography of BF neurons projecting to the sensory cortex}

We found retrobead-labeled neurons from three different sensory cortices within the HDB and $\mathrm{NB}$, which are cholinergic nuclei in the BF (Fig. 2A,B). Interestingly, we observed a clear distinction between the neurons that project into different sensory cortices. Neurons in the HDB preferentially project to V1, neurons in the $\mathrm{pNB}$ preferentially project to $\mathrm{A} 1$, and neurons in the anterior NB (aNB) preferentially project to S1 (Fig. $2 C$ ). We counted retrobead-labeled ChAT + and ChAT - neurons separately throughout the brain sections and found that $>90 \%$ of retrobead-labeled neurons were ChAT+ (see Fig. 5). In addition, these labeled ChAT + neurons showed clear topographic localization in the BF (Fig. 2C, top). Although we counted few retrobead-labeled ChAT- neurons, they also showed projection-specific localization within the BF (Fig. $2 C$, bottom). We found very few $\mathrm{BF}$ neurons labeled with both green and red retrobeads and the ones we did observe had little to no topographic bias in their localization (Fig. 2C, black bars). This suggests that $\mathrm{BF}$ neurons do not generally project to multiple sensory cortices simultaneously. Combined, our results show that BF neurons are topographically organized into distinct populations that project to sensory cortical areas processing sensory modality-specific information (Fig. $2 D, E$ ).

\section{Topography of LC neurons projecting to the sensory cortex} The LC is a small brainstem nucleus measuring $<1 \mathrm{~mm}$ in diameter, anterior to posterior. Noradrenergic neurons packed within 


\section{A}
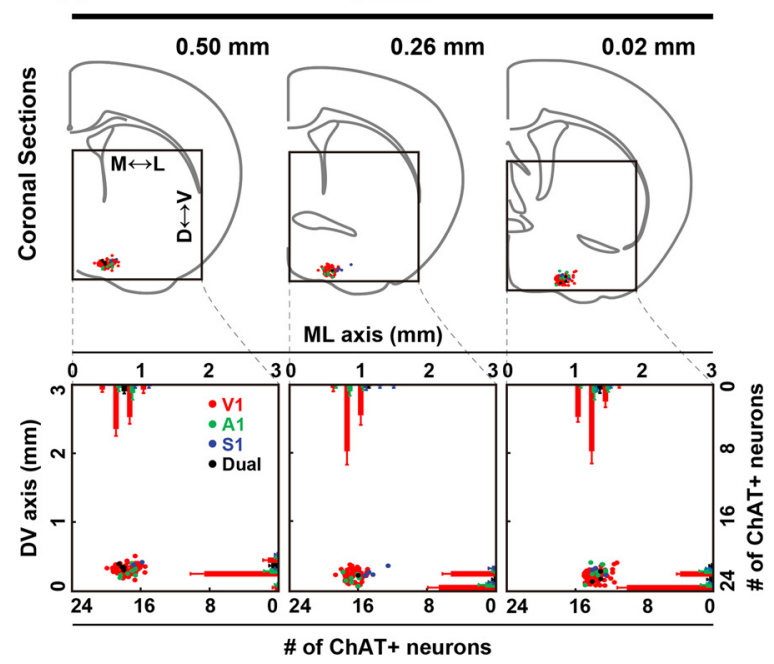

B $\quad$ aNB $\quad$ C $\quad$ pNB

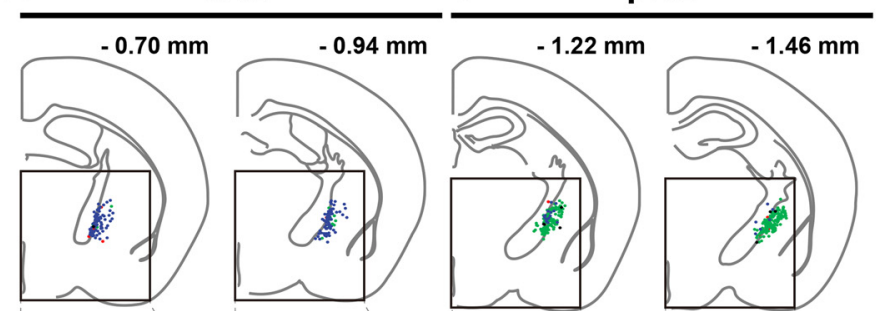

ML axis (mm)

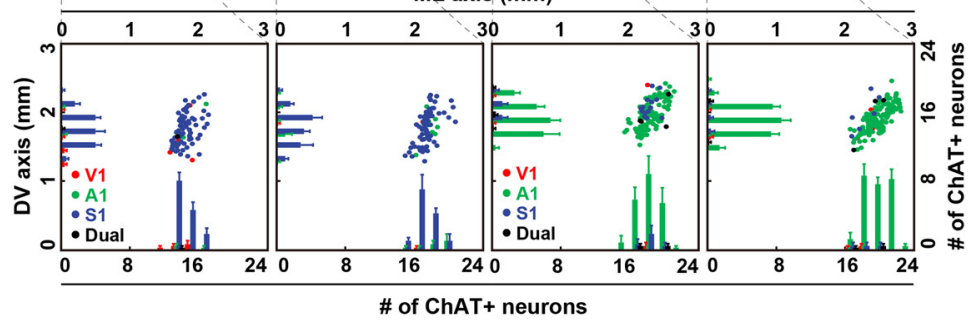

ML axis (mm)
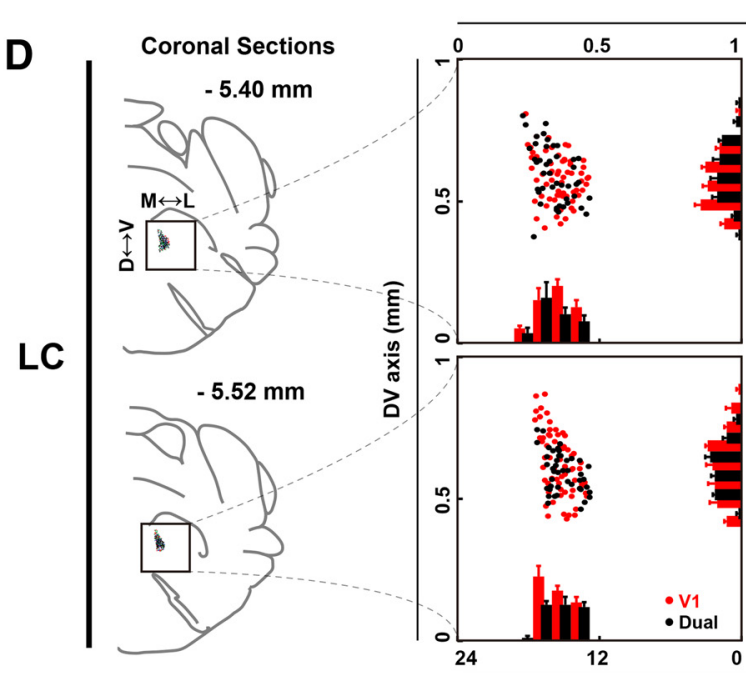

\section{5}

$10 \quad 0.5$

$\begin{array}{lll}10 & 0.5\end{array}$
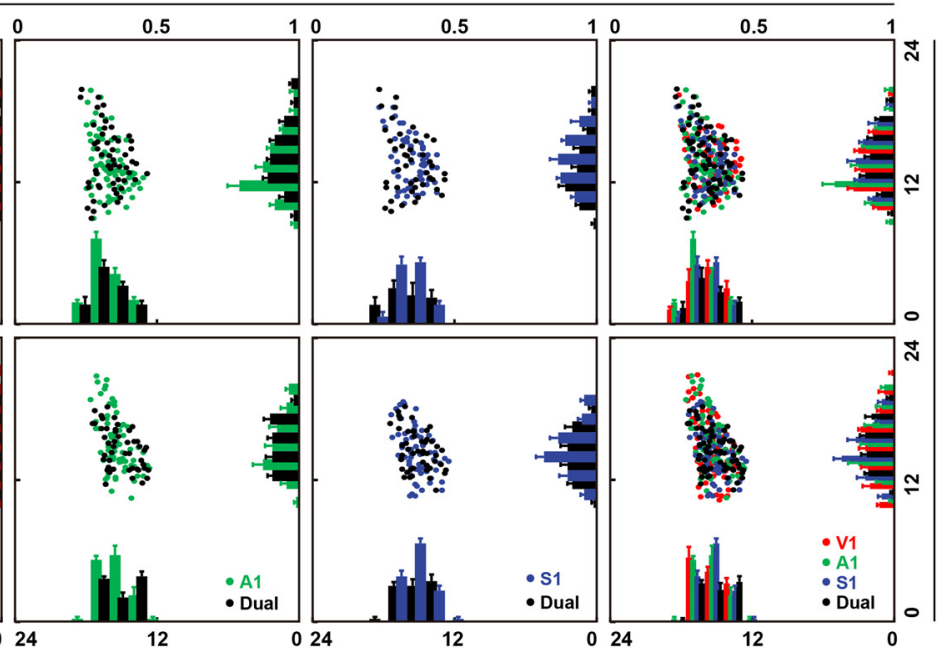

024

\# of $\mathrm{TH}+$ neurons

Figure 4. ML and DV localization of cholinergic BF and noradrenergic LC neurons projecting to sensory cortices. $\boldsymbol{A}$, Top, Schematic of representative coronal sections within the HDB. The topographic distribution of cholinergic neurons within the black square was analyzed along the ML and DV axes. Bottom, ML-DV scatter plot ( $3 \times 3 \mathrm{~mm}$ ) of the individual neurons overlaid with bar graphs (mean \pm SEM) indicating the number of retrobead-labeled neurons in each coronal section. Red, green, and blue circles and bars indicate neurons traced from V1, A1, and S1, respectively (i.e., unimodal projection neurons). Black circles and bars indicate neurons colabeled with both green and red retrobeads (i.e., bimodal projection neurons). Bin size for bar graphs, $0.2 \mathrm{~mm}$. $\boldsymbol{B}$, Same as $\boldsymbol{A}$, but for aNB. C, Same as $\boldsymbol{A}$, but for pNB. $\boldsymbol{D}$, Same as $\boldsymbol{A}$, but for noradrenergic LC neurons. Bin size for bar graphs, $0.067 \mathrm{~mm}$.

this small area project widely throughout the brain including many areas of the cortex (Swanson and Hartman, 1975; Loughlin et al., 1982; Waterhouse et al., 1983; Berridge and Waterhouse, 2003). When we performed the immunostaining, most LC neurons were $\mathrm{TH}$ positive $(\mathrm{TH}+)$. When we counted LC neurons labeled with green and red retrobeads (Fig. $3 B$ ), we found that many retrobead-labeled neurons were $\mathrm{TH}+$ as well (Fig. $3 \mathrm{C}$, right). We also found retrobead-labeled TH-negative (TH-) LC neurons (Fig. 3D), and to more clearly identify them, we costained the brain samples with the nuclear marker DAPI (Fig. $3 C, D)$. We observed both single-retrobead-labeled and doubleretrobead-labeled TH- neurons throughout the LC (Fig. 3E, bottom), with a slight concentration in the caudal LC.

Unlike the ChAT+ neurons in the BF, the $\mathrm{TH}+$ neurons in the LC that innervate $\mathrm{V} 1, \mathrm{~A} 1$, and $\mathrm{S} 1$ were intermingled, showing little to no bias in their topographic distribution along the AP axis (Fig. 3E, top). Interestingly, we found more neurons labeled with both colors of retrobeads among the $\mathrm{TH}+\mathrm{LC}$ neurons than among the ChAT + BF neurons, but these double-labeled neurons were distributed evenly throughout the LC (Fig. 3E, black bars). Thus, our results show an intermingling of the cell bodies of $\mathrm{TH}+$ noradrenergic neurons in the LC that project to V1, A1, and $\mathrm{S} 1$ and a broad distribution of the axon collaterals of these neurons into multiple sensory cortices.

\section{ML and DV topography of cholinergic and noradrenergic neurons projecting to the sensory cortex}

We next mapped the ML and DV distribution of ChAT + BF neurons and $\mathrm{TH}+\mathrm{LC}$ neurons by matching images of brain slices where we found the most labeled neurons to the coronal brain atlas (Fig. 4; see Materials and Methods). By quantifying the labeled neurons in the BF, we found a medioventral concentration of V1-projecting neurons (Fig. 4A), and a more laterodorsal concentration of S1-projecting and A1projecting neurons (Fig. 4B,C). This ML-DV distribution for the ChAT+ neurons follows the three-dimensional structure 
of the BF, which comprises the HDB at the anterior and medioventral location and the NB at the posterior and laterodorsal location. In contrast, $\mathrm{TH}+$ neurons projecting to $\mathrm{V} 1, \mathrm{~A} 1$, and S1 were located broadly throughout the LC. The V1projecting, A1-projecting, and S1-projecting retrobeadlabeled $\mathrm{TH}+$ neurons had indistinguishable $\mathrm{ML}$ and $\mathrm{DV}$ distributions in the LC, and the double-labeled neurons thoroughly intermingled with the single-labeled neurons (Fig. $4 D)$. Again, our results show that the neurons in the LC that innervate sensory cortices are evenly distributed throughout its three-dimensional structure.

\section{Cholinergic versus noradrenergic inputs to the sensory cortices}

We next asked how many of the retrobead-labeled neurons in the BF and LC were also immunostained. We found similar numbers of labeled neurons among the V1, A1, and S1 injections (Fig. $5 A, B$ ). We also found that in both the BF and LC, $>90 \%$ of the retrobead-labeled neurons were immunostained (Fig. 5C). This confirms that most neurons in the BF projecting to sensory cortices are cholinergic and most neurons in the LC projecting to sensory cortices are noradrenergic despite the existence of noncholinergic BF and non-noradrenergic LC neurons (Iijima, 1993; Gritti et al., 1997).

We next quantified neurons labeled with both red and green retrobeads-neurons that project simultaneously to two sensory cortices (bimodal projecting neurons; Fig. 5D-F, black bars). We found much more frequent colabeling among $\mathrm{TH}+$ neurons in the LC (up to $40 \%$ ) than among ChAT+ neurons in the $\mathrm{BF}(<10 \%$; Fig. $5 D-F$, top, black bars). In contrast, $\sim 20 \%$ of labeled noncholinergic neurons in the BF and nonnoradrenergic neurons in the LC were labeled with both colors of retrobeads (Fig. 5D-F, bottom). This suggests that these populations do not follow the projection-selectivity rules we observed among the cholinergic and noradrenergic populations. We further calculated a selectivity index for the BF and LC neurons by normalizing the number of labeled cells with unimodal projections (Fig. 5G). We observed a significantly higher level of selectivity among the ChAT + BF neurons than among the $\mathrm{TH}+\mathrm{LC}$ neurons and no difference between the intermediate level of projection selectivity observed among the ChAT - and $\mathrm{TH}-$ neurons. Thus, cholinergic BF neurons show the highest selectivity, while divergence is more the rule among noradrenergic LC neurons. Interestingly, we observed that, within the same brain, each injection of retrobeads into a specific sensory cortex tended to label more noradrenergic neurons than cholinergic neurons (Fig. $5 H)$. This suggests that the divergence of the $\mathrm{TH}+$ neuron axon collaterals into the injection site allows the retrobeads to label more LC neurons than BF neurons. Together, our results demonstrate that individual noradrenergic LC neurons send divergent projections into multiple sensory cortices, whereas cholinergic BF neurons selectively project to distinct sensory cortices.

\section{Validation of the projection selectivity}

To further validate the selectivity of BF and LC projections, we injected mixed green and red retrobeads into V1 (Fig. 6A-C, top row). When we did this, most of the labeled BF and LC neurons were colabeled with both green and red retrobeads (Fig. 6, Mixture). This proves that the selective labeling we observed among the cholinergic BF neurons in earlier experi- ments was not due to some limitation in the retrobead colabeling of BF neurons.

Since it is possible that the differential selectivity we observed in BF and LC projections to sensory cortices is due to some difference in the ability of the retrobeads to spread in each location, we compared the results of single 200-300 nl retrobead injections into V1 and A1 (Fig. 6, Single) with three closely spaced injections of similar volumes totaling 600-900 $\mathrm{nl}$ of retrobeads into the same locations (Fig. 6, Triple). We observed retrobead spreading along the AP axis that ranged from 120 to $780 \mu \mathrm{m}$ in the single injection condition and from 900 to $1080 \mu \mathrm{m}$ in the triple injection condition (Fig. $6 \mathrm{~F}, \mathrm{H}$; $\left.{ }^{* * *} p<0.001\right)$. Despite this significant difference in retrobead spreading, we still observed higher projection selectivity in the BF neurons than in the LC neurons in both the single and triple injection conditions (Fig. 6D-H). In other words, the selectivity of $\mathrm{BF}$ and $\mathrm{LC}$ projections as measured by dual retrograde tracing does not originate in physical limitations of retrobead spreading at the injection sites. This means our dual retrograde tracing technique is reliable enough to demonstrate true divergence among the axonal projections of subcortical neuromodulatory centers to specific cortical areas.

\section{Modality-selective cholinergic versus broad noradrenergic modulation of sensory cortices}

We have identified three populations of cholinergic BF neurons along the AP axis that project with distinct topography to sensory cortices in a modality-specific manner. Neurons in the $\mathrm{HDB}$ preferentially project to $\mathrm{V} 1$, neurons in the aNB to S1, and neurons in the pNB to A1. We next asked whether the anatomic topography we observed in cholinergic BF projections indeed mediates selective modulation of distinct sensory cortices. To answer this question, we optogenetically activated cholinergic neurons in the HDB (Fig. $7 A-F$ ) or pNB (Fig. $7 G-L)$ of ChAT-Channelrhodopsin-2 (ChAT-ChR2) mice, which express ChR2-EYFP in $\geq 90 \%$ of their cholinergic neurons (Fig. $7 \mathrm{~B}, \mathrm{H}$ ). During optogenetic activation, we measured LFPs in V1 and A1, quantifying desynchronization (Fig. $7 C, I)$ by computing the ratio of the high-frequency LFP power spectrum $(30-80 \mathrm{~Hz})$ to the low-frequency LFP power spectrum (1-10 Hz; Goard and Dan, 2009; Pinto et al., 2013). As expected because of the anatomic selectivity of HDB cholinergic projections to $\mathrm{V} 1$, optogenetic activation of $\mathrm{HDB}$ cholinergic neurons induced significant desynchronization in $\mathrm{V} 1$, but not A1 (Fig. 7C-F). Conversely, optogenetic activation of pNB cholinergic neurons induced significant desynchronization in A1, but not V1 (Fig. 7I-L).

Next, we further confirmed the selective modulation of $\mathrm{V} 1$ and $\mathrm{A} 1$ by cholinergic BF projections by performing simultaneous LFP recordings using a double-shank LCP probe inserted into both $\mathrm{V} 1$ and $\mathrm{A} 1$ simultaneously (Fig. 7D-F, $-L$, red lines). As expected, we observed significant and selective desynchronization in V1 with blue light stimulation of the $\mathrm{HDB}$ and in $\mathrm{A} 1$ with stimulation of the $\mathrm{pNB}$ (Fig. $7 F, L$ ). Thus, we have demonstrated that the anatomic selectivity of cholinergic BF projections to the sensory cortices is also physiologically relevant.

Last, we used TH-ChR2 mice to measure LFPs in specific sensory cortices during optogenetic stimulation of $\mathrm{TH}+$ noradrenergic LC neurons (Fig. 8). In contrast to our results with cholinergic BF neuron activation, noradrenergic LC neuron activation with the same blue-light intensity through the same-thickness optic fiber induced significant desynchroniza- 
A

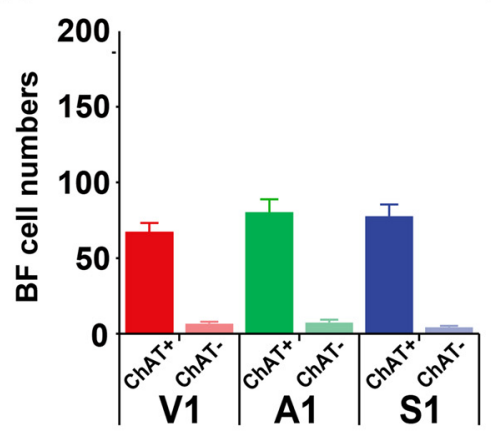

B

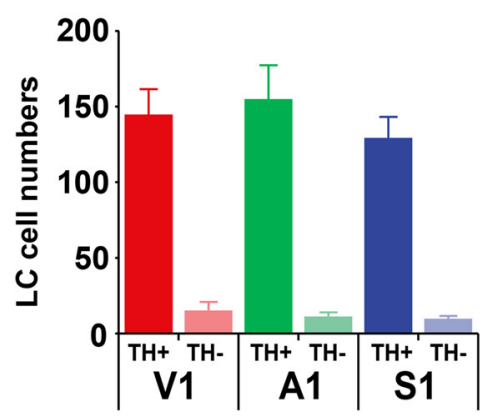

E

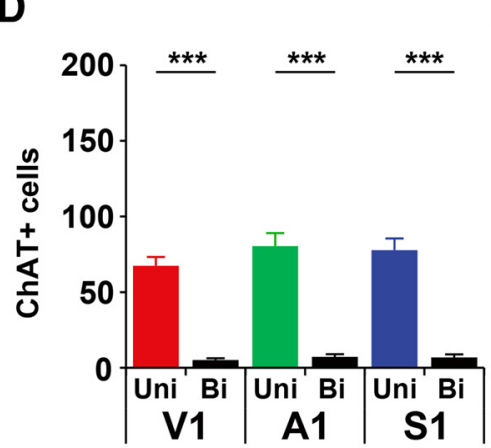

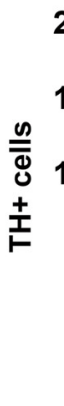

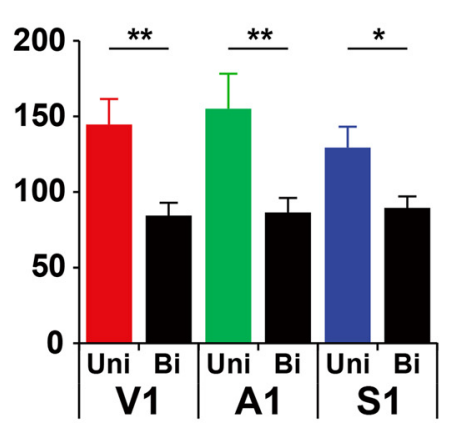

C

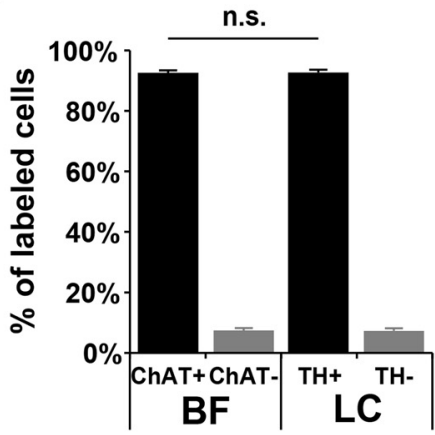

F

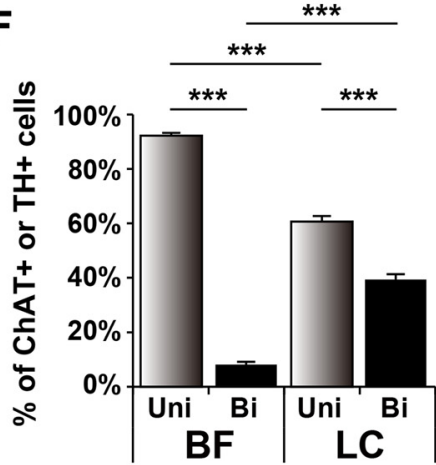

n.s.
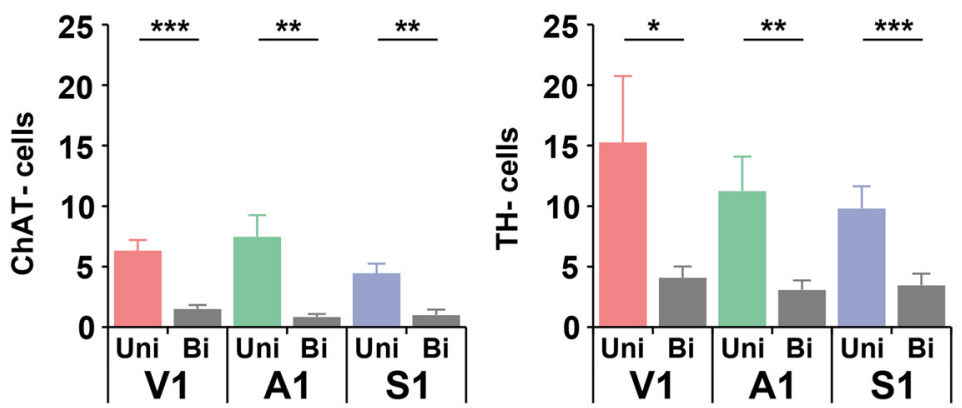

G

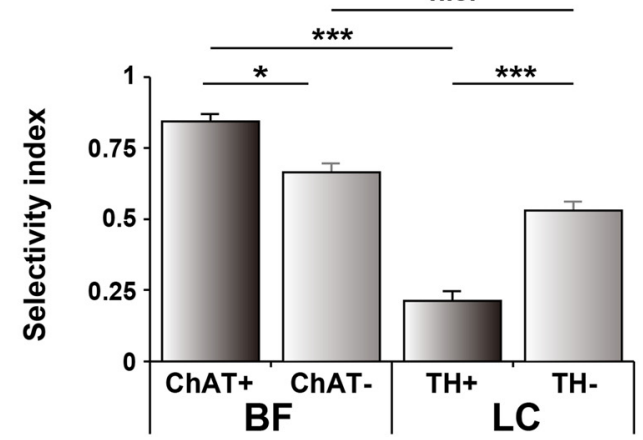

H

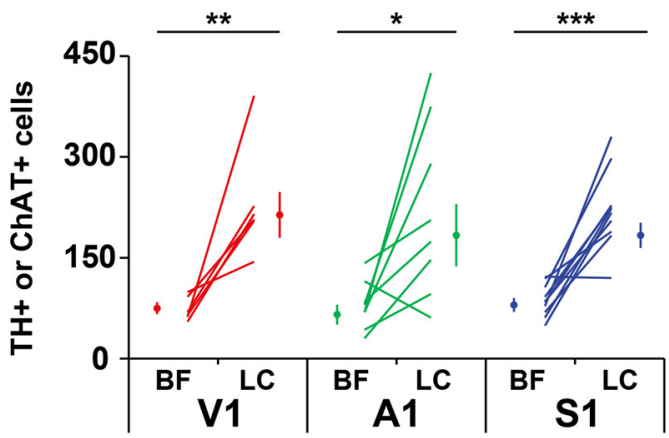

Figure 5. Selectivity of the BF and LC inputs to sensory cortices. $A$, Number of ChAT + and ChAT - BF cells projecting into V1 $(n=12), A 1$ ( $n=13)$, and $S 1$ ( $n=11)$. $B$, Same as $A$, but for TH + and TH $-\mathrm{LC}$ cells $(\mathrm{V} 1, n=11 ; \mathrm{A1}, n=12 ; \mathrm{S1}, n=11)$. Bars, mean \pm SEM. C, ChAT + and TH + neurons as a percentage of the total retrobead-labeled neurons in the BF $(n=36)$ and $\mathrm{LC}(n=$ 34), respectively. Note that there are no significant differences between the percentage of ChAT+BF and TH $+\mathrm{LC}$ neurons (n.s., not significant; unpaired $t$ test). $\boldsymbol{D}$, Selective projections of cholinergic BF neurons to the primary sensory cortices. Numbers of ChAT + (top) and ChAT - (bottom) neurons in the three experimental groups (V1-A1, V1-S1, A1-S1). Red, green, and blue bars indicate neurons showing modality-selective projections to V1, A1, and S1, respectively (Uni; mean \pm SEM). Black bars indicate neurons colabeled with both green and red retrobeads, meaning they send their axons into two sensory cortices (Bi; mean $\pm \mathrm{SEM}$ ). Uni indicates unimodel projections. Bi indicates bimodal projections. V1, $n=24 ; \mathrm{A1}, n=26 ; \mathrm{S1}, n=22$. ${ }^{* * *} p<0.001$; ${ }^{* *} p<0.01$; ${ }^{*} p<0.5$ (paired $t$ test). $\boldsymbol{E}$, Divergent projections of $\mathrm{L} C$ neurons into the primary sensory cortices; same as $\boldsymbol{D}$, but for $\mathrm{TH}+$ (top) and $\mathrm{TH}-$ (bottom) $\mathrm{LC}$ neurons $(\mathrm{V} 1, n=22 ; \mathrm{A} 1, n=24 ; \mathrm{S} 1, n=22)$. Bars, mean \pm SEM. $F$, Unimodal and bimodal projecting neurons as a percentage of the total $\mathrm{ChAT}+\mathrm{BF}$ and $\mathrm{TH}+\mathrm{LC}$ neurons (top) and the ChAT $-\mathrm{BF}$ and $\mathrm{TH}-\mathrm{LC}$ neurons (bottom). ${ }^{* * *} p<0.001$; n.s., not significant (unpaired $t$ test). G, Selectivity index for BF and LC neurons innervating the sensory cortices (mean \pm SEM). Note that ChAT + BF neurons show the highest selectivity. ChAT+ $\mathrm{BF}, n=36 ; \mathrm{ChAT}-\mathrm{BF}, n=36 ; \mathrm{TH}+\mathrm{LC}, n=34 ; \mathrm{TH}-\mathrm{LC}, n=34 .{ }^{* * *} p<0.001 ;{ }^{*} p<0.05 ;$ n.S., not significant (unpaired $t$ test). $\boldsymbol{H}$, Number of cholinergic $\mathrm{BF}$ and noradrenergic $\mathrm{LC}$ neurons traced from the same primary sensory cortices. Number of immunostained, retrobead-labeled neurons traced from V1 (red; $n=6$ ), A1 (green; $n=8$ ), and S1 (blue; $n=10$ ) in the BF and LC. ${ }^{*} p<0.05$; ${ }^{* *} p<0.01 ;{ }^{* * *} p<0.001$ (paired $t$ test). $n$ represents the number of injection sites. 
A
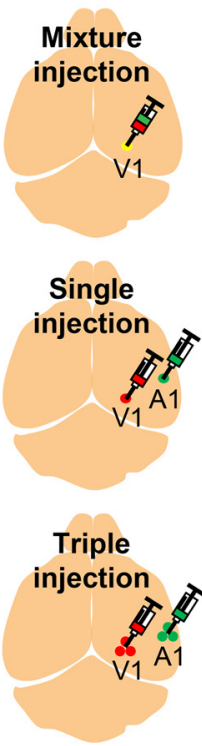

D

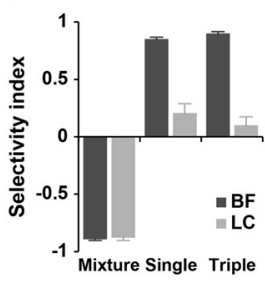

B
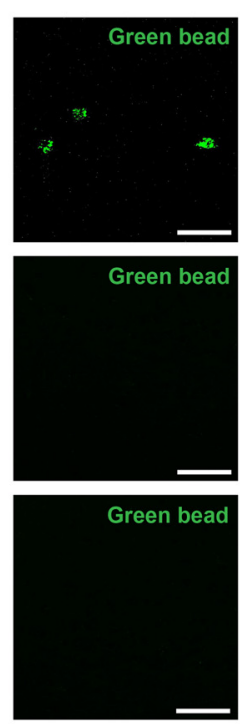

E

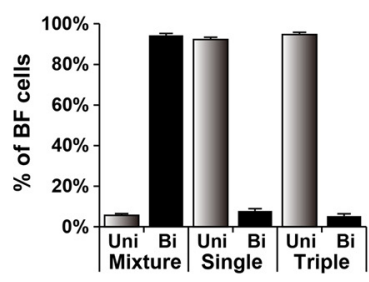

Basal Forebrain (HDB)
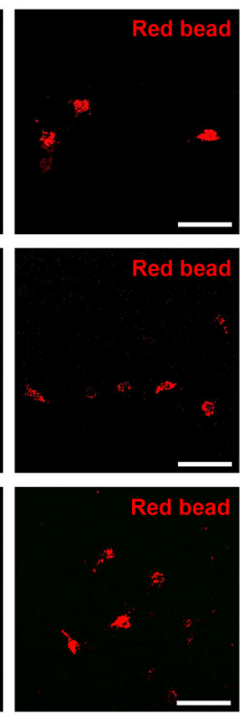

$\mathbf{F}$
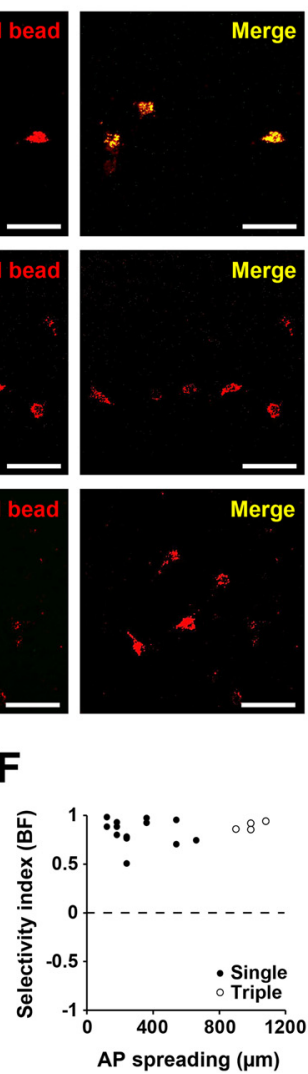

C
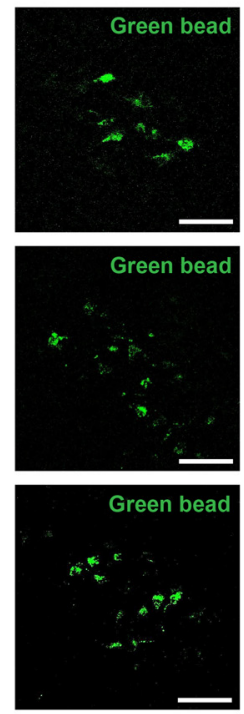

G

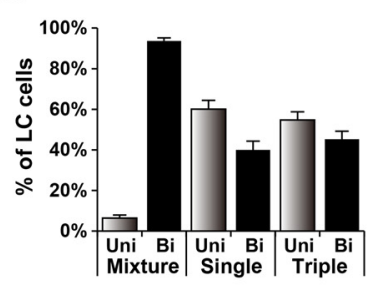

Locus Coeruleus
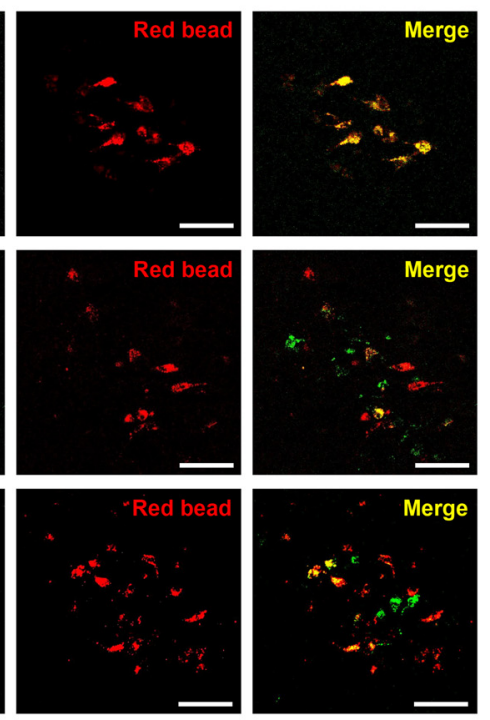

H

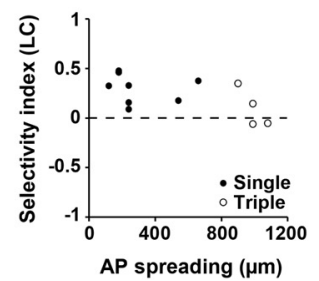

Figure 6. The selectivity of BF projections to the sensory cortex is not an artifact of limitations in retrobead uptake or spreading. $\boldsymbol{A}$, Three dual retrobead injection methods: mixture (top), single (middle), and triple (bottom) injection of green and red retrobeads. For each dual injection, red retrobeads were injected into $\mathrm{V} 1$ and green retrobeads into A1. $\boldsymbol{B}$, Representative images of retrobead-labeled neurons in the HDB. When we injected mixed retrobeads into V1, almost all the retrobead-labeled neurons were colabeled with green and red retrobeads (top). In the V1-A1 case, in which we injected only red retrobeads into V1, we only found red-labeled neurons in the HDB (middle and bottom). $C$, Same as $B$, but in the LC. LC neurons were colabeled with both green and red retrobeads in the case of mixed injections into V1 (top) or with single and triple V1-A1 dual injections (middle and bottom). $\boldsymbol{D}$, Selectivity index for BF and LC neurons in the mixture, single, and triple injection groups (mean \pm SEM). $\boldsymbol{E}$, Unimodal and bimodal projecting neurons as a percentage of total retrobead-labeled neurons in the BF. $F$, Scatter plot of anterior-to-posterior retrobead spreading around the injection sites versus the selectivity index observed with each V1-A1 dual-injection method. Note that BF neurons show high levels of projection selectivity regardless of retrobead spreading. $\boldsymbol{G}, \boldsymbol{H}$, Same as $\boldsymbol{E}$ and $\boldsymbol{F}$, but for $L C$ neurons. Note that $L C$ neurons show similar levels of selectivity with the single and triple injection methods.

tion in V1, A1, and S1 (Fig. 8C,D). Although we were unable to record from $\mathrm{S} 1$ during BF stimulation because the areas targeted with the optic fiber and the recording probe were too close together, we were able to record from S1 during LC stimulation. Consistent with the divergent anatomic projections we observed among noradrenergic LC neurons, we observed similar levels of desynchronization across all three sensory cortices (Fig. 8E). We further confirmed simultaneous noradrenergic modulation of $\mathrm{V} 1$ and $\mathrm{A} 1$ by recording from both sensory cortices at the same time using a double-shank LCP probe (Fig. 8 D, E, red lines). Together, our data demonstrate discrete cholinergic innervation of specific sensory cortices that selectively induces sensory modality-specific modulation while noradrenergic projections diverge to modulate multiple sensory cortices simultaneously (Fig. 9).

\section{Discussion}

In this study, we examined the $\mathrm{BF}$ and $\mathrm{LC}$ projections to determine the extent to which they show anatomic and functional selectivity for specific sensory cortices. We found that while cholinergic BF projections are discrete and mediate highly selective modulation of the sensory cortex, noradrenergic LC projections diverge onto multiple sensory cortices (for schematic illustrations, see Fig. 9). Our results provide insight into the anatomic and physiological basis of cholinergic and noradrenergic neuromodulation of the sensory cortex and provide examples of two distinct patterns of subcortical-to-cortical connectivity in the mammalian brain.

We observed distinct modality-specific topography among cholinergic BF neurons projecting to the $\mathrm{V} 1, \mathrm{~A} 1$, and $\mathrm{S} 1$ sensory cortices. In the rat brain, corticopetal cholinergic BF neurons seem to also show topographic organization (Bigl et al., 1982; Rye et al., 1984). Noradrenergic LC neurons, however, despite also innervating the primary sensory cortices, do not show any topographic specificity. How do these contrasting projection patterns in the cholinergic BF and noradrenergic LC projections arise in the mammalian cortex? Although the noradrenergic LC neurons project widely throughout the forebrain (Samuels and Szabadi, 2008), the LC is a relatively small nucleus packed with noradrenergic neurons (Fig. 3, immunostaining data). It is possible limited space in the LC hinders the development of internal subnuclei projecting to distinct sensory cortices, resulting in individual noradrenergic neurons with highly divergent projections. The BF is much larger and contains more neurons than the LC (Sturrock and Rao, 1985; Perez et al., 2007). The BF also includes several 
A

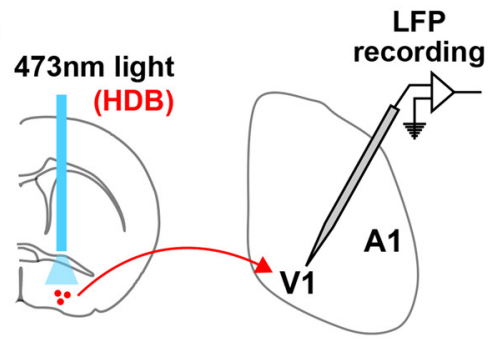

C

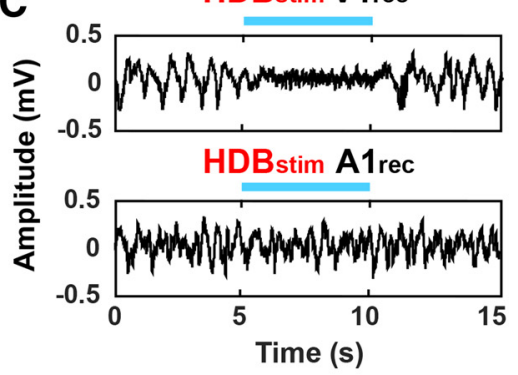

G

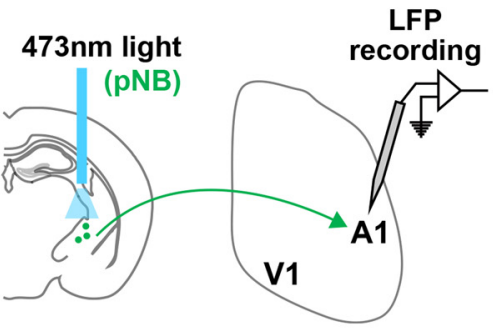

B
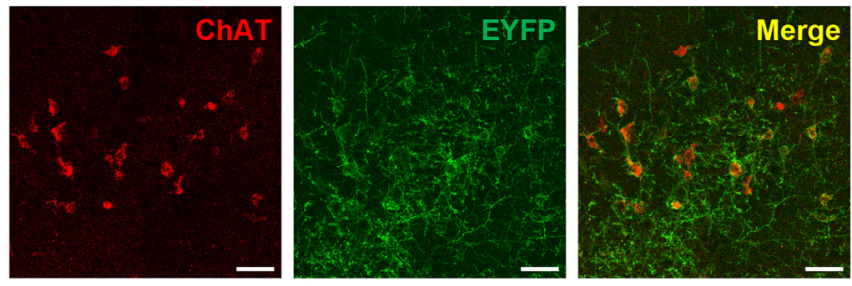

E

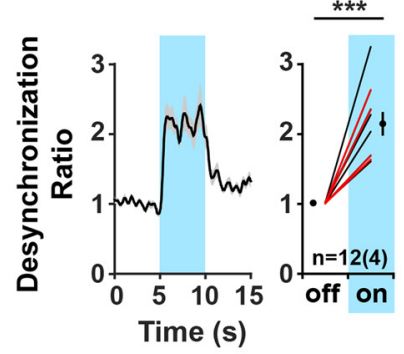

E

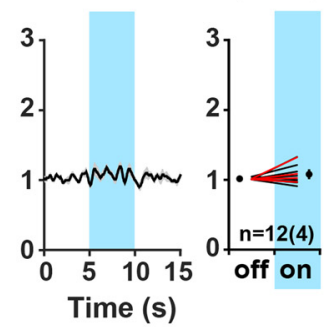

F

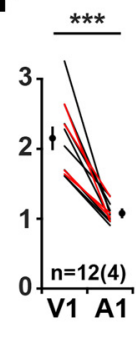

H
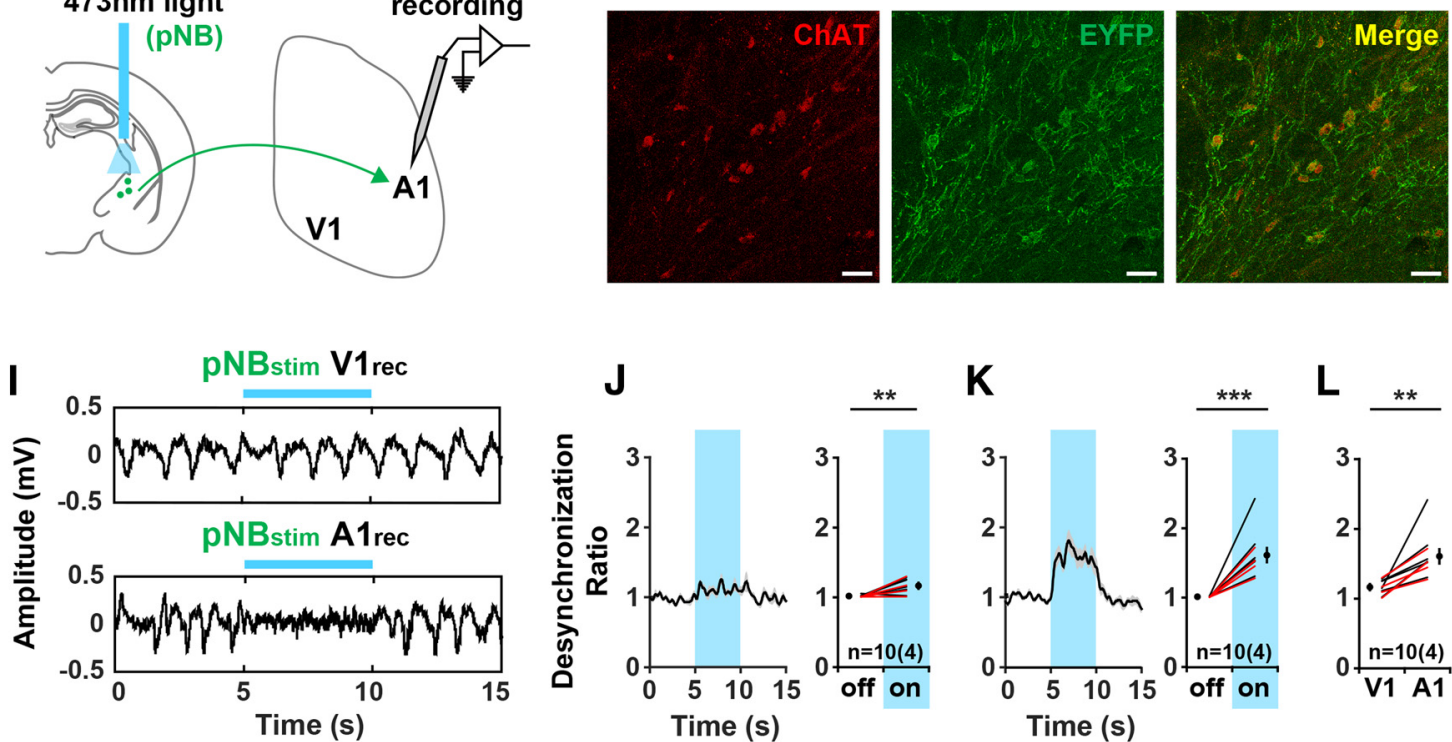

K

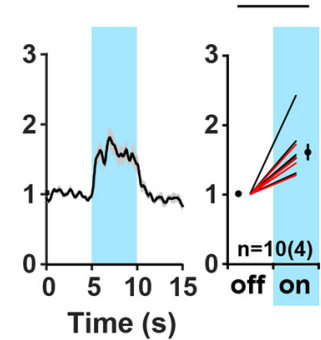

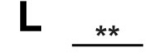

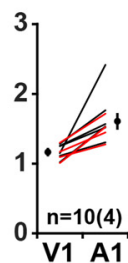

Figure 7. Optogenetic activation of cholinergic BF neurons selectively modulates V1 and A1. $A$, Experimental schematic for the optogenetic stimulation of HDB cholinergic neurons and LFP recordings in ChAT-ChR2-EYFP mice. B, ChAT-immunostained fluorescence images of the HDB in a ChAT-ChR2-EYFP mouse. Red, ChAT; green, ChR2-EYFP; scale bars, 50 $\mu$ m. C-F, LFP changes in V1 and $A 1$ induced by optogenetic activation of cholinergic BF neurons ( $n=12 ; 8$ mice with a single-shank probe and 4 mice with a double-shank probe). $C$, Representative LFP traces recorded in V1 (top) and A1 (bottom). $\boldsymbol{D}, \boldsymbol{E}$, Time course (left; black line, mean; gray shading, \pm SEM) and the average (right; black circle, mean; error bars, \pm SEM; black lines, individual recording pairs) desynchronization ratio (power at $30-80 \mathrm{~Hz}$ divided by power at $1-10 \mathrm{~Hz}$ ) in V1 ( $\boldsymbol{D}$; ${ }^{* * *} p<0.001$ ) and $\mathrm{A} 1$ ( $\boldsymbol{E}$; n.S., not significant). Blue bars in $\boldsymbol{C}$ and blue shading in $\boldsymbol{D}$ and $\boldsymbol{E}$ indicate the laser stimulation period. $\boldsymbol{F}$, Comparison of the desynchronization ratio between V1 and A1 during laser stimulation of the HDB $\left({ }^{* * *} p<0.001\right)$. Black circle, Mean; error bars, \pm SEM; black lines, individual recording pairs. Red lines in $\boldsymbol{D}$ and $\boldsymbol{F}$ indicate simultaneous $V 1$ and $A 1$ recordings via a double-shank $L(P$ probe ( $n=4$ animals). $\mathbf{G}-\boldsymbol{L}$, Same as $\boldsymbol{A}-\boldsymbol{F}$, but for optogenetic stimulation of the cholinergic neurons in pNB ( $n=10 ; 6$ mice with a single-shank probe and 4 mice with a double-shank probe). $\boldsymbol{J},{ }^{* *} p<0.01 ; \boldsymbol{K}_{,}{ }^{* *} p<0.001 ; \boldsymbol{L},{ }^{* *} p<0.01$. Paired $t$ test for all statistics.

subnuclei in which the cholinergic neurons are not even the major population (Gritti et al., 2006; Henny and Jones, 2008). Thus, cholinergic BF neurons are distributed sparsely over a larger area. Furthermore, with more potential axonal trajectories from the $\mathrm{BF}$ to the cortex, there is a greater chance for cholinergic axons to be guided into distinct cortical areas (Mesulam et al., 1983; Woolf, 1991). The topographic distinction of the cholinergic BF projections into the primary sensory cortices may therefore naturally arise from the structure of the BF. Then, the selectivity of individual cholinergic neurons may simply emerge from this an- atomic property of the BF. Future studies on the molecular and physiological mechanisms of axon guidance among BF and LC projections will clarify the development of these subcortical-tocortical neuromodulatory circuits with different levels of selectivity.

Our retrograde tracing experiments also showed that most of the neurons innervating sensory cortices from the BF are cholinergic and most from the LC are noradrenergic. We observed that $\sim 10 \%$ of the retrobead-labeled neurons were ChAT - or $\mathrm{TH}-$. Both the BF and LC contain other types of neurons. The BF 
A
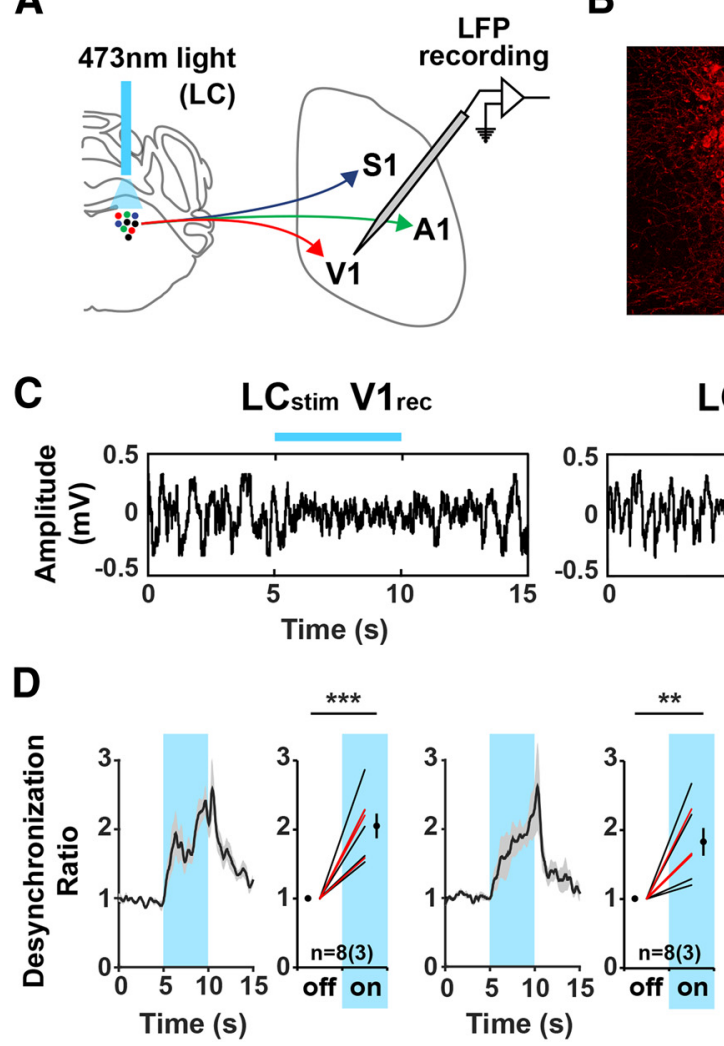

B
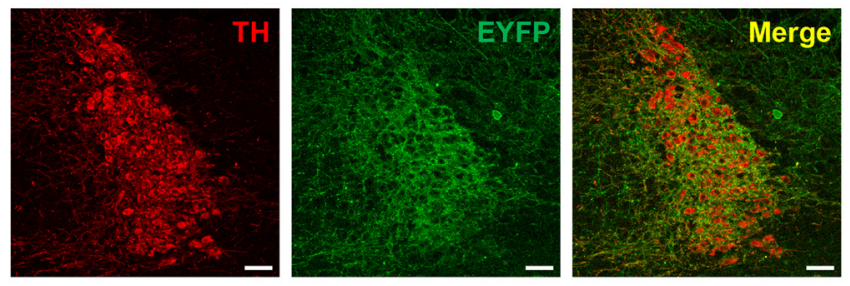

LC stim A1 rec $_{\text {rec }}$

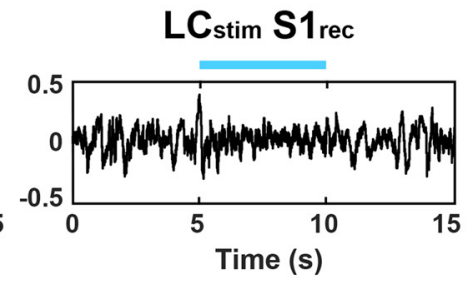

E

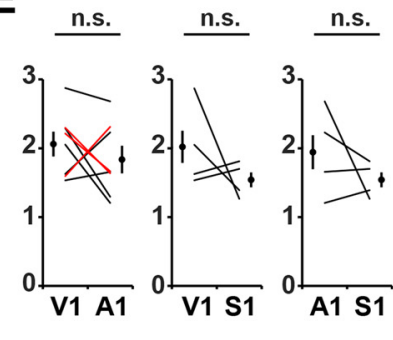

Figure 8. Noradrenergic $\mathrm{LC}$ neurons broadly modulate the sensory cortices. $A$, Experimental schematic for optogenetic stimulation of the noradrenergic $\mathrm{LC}$ neurons and $\mathrm{LFP}$ recordings in TH-ChR2-EYFP mice. B, TH-immunostained fluorescence images of the LC in a TH-ChR2-EYFP mouse. Red, TH; green, ChR2-EYFP; scale bars, $50 \mu \mathrm{m}$. C-E, LFP changes in V1, A1, and S1 induced by optogenetic activation of noradrenergic LC neurons ( $n=8 ; 5$ mice with a single-shank probe and 3 mice with a double-shank probe). C, Representative LFP traces recorded in V1 (left), A1 (middle), and S1 (right). $\boldsymbol{D}$, Time course (left; black line, mean; gray shading, \pm SEM) and the average (right; black circle, mean; error bars, \pm SEM; black lines, individual recording pairs) desynchronization ratio in V1 (left; ${ }^{* * *} p<0.001$ ), A1 (middle; ${ }^{* *} p<0.01$ ), and S1 (right; ${ }^{*} p<0.05$ ). Blue bars in Cand blue shading in $\boldsymbol{D}$ indicate the laser stimulation period. $\boldsymbol{E}$, Comparison of the desynchronization ratio among V1, A1, and S1 during laser stimulation of the LC (n.S., not significant). Black circle, mean; error bars, \pm SEM; black lines, individual recording pairs. Red lines in $\boldsymbol{D}$ and $\boldsymbol{E}$ indicate simultaneous $\mathrm{V} 1$ and $\mathrm{A} 1$ recordings via a double-shank LCP probe ( $n=3$ animals).

contains glutamatergic and GABAergic neurons (Brashear et al., 1986; Gritti et al., 2006) that also project into the cortex (Gritti et al., 1997; Henny and Jones, 2008). The projections of these neurons into different sensory cortices, however, remain poorly understood. Similarly, GABAergic and indolaminergic neurons intermingle with noradrenergic neurons in the LC (Iijima and Ohtomo, 1988; Iijima, 1989, 1993; Iijima and Sato, 1991; Jones, 1991), but whether these nonnoradrenergic neurons innervate sensory cortices is unknown. We have shown that small numbers $(<10 \%)$ of noncholinergic and nonnoradrenergic neurons in the BF and LC do indeed innervate sensory cortices with intermediate levels of selectivity (Fig. $5 G$ ). Even though there are fewer ChAT + neurons than ChAT - neurons in the BF (Gritti et al., 2006; Henny and Jones, 2008), neurons projecting to the sensory cortex are mostly cholinergic neurons. Thus, although noncholinergic neurons intermingle with cholinergic neurons in the BF and non-noradrenergic neurons intermingle with noradrenergic neurons in the LC, each population seems to use a different strategy for wiring itself into the sensory cortex. Future studies will clarify the functional roles these noncholinergic and nonnoradrenergic projections play in the cortex.

The distinct anatomic projection patterns of cholinergic BF and noradrenergic LC neurons suggest differences in the functional selectivity with which they modulate the cortex. We found optogenetic stimulation of the local nuclei in the basal forebrain induced desynchronization only in specific sensory cortices, while stimulation of noradrenergic LC neurons induced broad desynchronization in multiple sensory cortices. This is strong evidence that, as implied by their anatomy, cholinergic modulation is selective and discrete whereas noradrenergic modulation broadly covers multiple sensory cortices. Recently, Schwartz et al. showed that the noradrenergic LC neurons project broadly to different cortical and subcortical areas (Schwarz et al., 2015). This is consistent with our findings and suggests high levels of divergence may be a general feature of noradrenergic LC projections, allowing them to modulate broad areas throughout the brain. Activation of noradrenergic LC neurons facilitates wakefulness in freely moving animals (Carter et al., 2010). Since animal brains must make sweeping state changes when transitioning from sleep to wakefulness, the anatomic and functional divergence of noradrenergic LC projections make these neurons likely mediators of this transition.

Why should then the cholinergic BF projections to the sensory cortices be so selective? The cerebral cortex is divided into defined functional units, with each area of primary sensory cortex specialized for the encoding and processing of a single sensory modality. Sensory cortex activity can be dynamically modulated in behaving animals to enhance or suppress its ability to process sensory information (Lee and Dan, 2012; Harris and MrsicFlogel, 2013). This modulation of sensory cortical activity is likely a key feature of attention (Harris and Thiele, 2011). Although subcortical-to-cortical neuronodulatory projections are known 
A

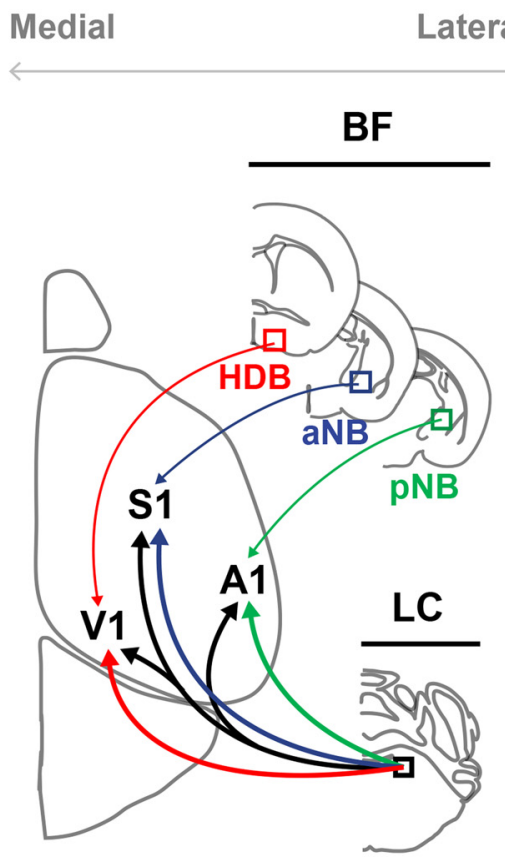

B

Anterior Posterior

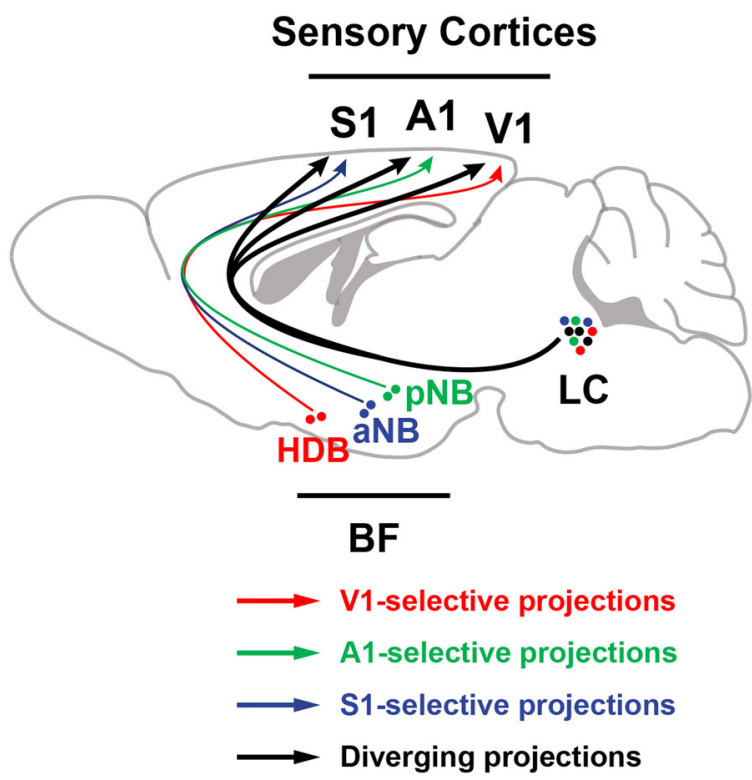

Figure 9. Schematic indicating selective BF and divergent LC projections into V1, A1, and S1. A, Top and coronal views of the brain areas, including the sensory cortices, the BF, and the LC. Black arrows, diverging inputs; colored arrows, selective inputs (red for V1-selective, green for A1-selective, and blue for S1-selective projections). $\boldsymbol{B}$, Sagittal view of the brain illustrating the selective BF and divergent $\mathrm{LC}$ projections into $\mathrm{V} 1, \mathrm{~A} 1$, and $\mathrm{S} 1$.

to be important for attentional modulation of the sensory cortex, a gap in our understanding remains. Since most neuromodulators are thought to be released broadly by highly divergent axonal projections, it is unclear how subcortical-to-cortical projections can modulate attention to specific types of sensory information. Our findings on the anatomic selectivity by which cholinergic BF projections modulate the sensory cortices help clarify this mystery. Future experiments aimed at dissecting the direct and indirect interactions between $\mathrm{BF}$ subnuclei projecting to distinct sensory cortices in awake, behaving animals will help clarify in vivo mechanisms of selective operation of individual BF projections. It might be possible that learning and memory of specific sensory features of the environment facilitate independent regulation of each cholinergic projection and vice versa (Woolf, 1996). In any case, selective cholinergic projections provide a platform for modality-selective neuromodulation in vivo. Our results suggest individual cholinergic BF neurons can exert selective modulation of a specific primary sensory cortex, and this might be important for attention to information of its corresponding sensory modality.

The cortex needs at least two distinct modulatory switches: a "hub" switch for inducing changes throughout the entire cortex, and a "local" switch for enhancing efficiency in specific areas as needed. In other words, while broad changes occur for sleepwakefulness transitions, local changes are necessary to dynamically adjust cortical function for rapid processing of specific types of information. The hub switch may also be necessary for multisensory coordination, whereas the local switch may allow for selective attention to a specific sensory modality. Our data support the idea that the noradrenergic LC projections may contribute to the hub switch, while cholinergic BF projections may contribute to the local switch. Future studies will clarify the behavioral impact that broad noradrenergic and selective cholin- ergic modulation of the sensory cortex has on the maintenance of selective attention on specific types of sensory information.

\section{References}

Aston-Jones G, Rajkowski J, Kubiak P, Alexinsky T (1994) Locus coeruleus neurons in monkey are selectively activated by attended cues in a vigilance task. J Neurosci 14:4467-4480. Medline

Berridge CW, Waterhouse BD (2003) The locus coeruleus-noradrenergic system: modulation of behavioral state and state-dependent cognitive processes. Brain Res Rev 42:33-84. CrossRef Medline

Bigl V, Woolf NJ, Butcher LL (1982) Cholinergic projections from the basal forebrain to frontal, parietal, temporal, occipital, and cingulate cortices: a combined fluorescent tracer and acetylcholinesterase analysis. Brain Res Bull 8:727-749. CrossRef Medline

Bloem B, Schoppink L, Rotaru DC, Faiz A, Hendriks P, Mansvelder HD, van de Berg WD, Wouterlood FG (2014) Topographic mapping between basal forebrain cholinergic neurons and the medial prefrontal cortex in mice. J Neurosci 34:16234-16246. CrossRef Medline

Brashear HR, Zaborszky L, Heimer L (1986) Distribution of gabaergic and cholinergic neurons in the rat diagonal band. Neuroscience 17:439-451. CrossRef Medline

Carter ME, Yizhar O, Chikahisa S, Nguyen H, Adamantidis A, Nishino S, Deisseroth K, de Lecea L (2010) Tuning arousal with optogenetic modulation of locus coeruleus neurons. Nat Neurosci 13:1526-1533. CrossRef Medline

Castro-Alamancos MA, Gulati T (2014) Neuromodulators produce distinct activated states in neocortex. J Neurosci 34:12353-12367. CrossRef Medline

Constantinople CM, Bruno RM (2011) Effects and mechanisms of wakefulness on local cortical networks. Neuron 69:1061-1068. CrossRef Medline

Corbetta M, Shulman GL (2002) Control of goal-directed and stimulusdriven attention in the brain. Nat Rev Neurosci 3:201-215. Medline

Eggermann E, Kremer Y, Crochet S, Petersen CC (2014) Cholinergic signals in mouse barrel cortex during active whisker sensing. Cell Rep 9:16541660. CrossRef Medline

Felleman DJ, Van Essen DC (1991) Distributed hierarchical processing in the primate cerebral cortex. Cereb Cortex 1:1-47. Medline 
Franklin KBJ, Paxinos G (2008) The mouse brain in stereotaxic coordinates, 3rd edition. Amsterdam: Elsevier.

Fries P, Reynolds JH, Rorie AE, Desimone R (2001) Modulation of oscillatory neuronal synchronization by selective visual attention. Science 291: 1560-1563. CrossRef Medline

Goard M, Dan Y (2009) Basal forebrain activation enhances cortical coding of natural scenes. Nat Neurosci 12:1444-1449. CrossRef Medline

Gritti I, Mainville L, Mancia M, Jones BE (1997) GABAergic and other noncholinergic basal forebrain neurons, together with cholinergic neurons, project to the mesocortex and isocortex in the rat. J Comp Neurol 383: 163-177. Medline

Gritti I, Henny P, Galloni F, Mainville L, Mariotti M, Jones BE (2006) Stereological estimates of the basal forebrain cell population in the rat, including neurons containing choline acetyltransferase, glutamic acid decarboxylase or phosphate-activated glutaminase and colocalizing vesicular glutamate transporters. Neuroscience 143:1051-1064. CrossRef Medline

Harris KD, Mrsic-Flogel TD (2013) Cortical connectivity and sensory coding. Nature 503:51-58. CrossRef Medline

Harris KD, Thiele A (2011) Cortical state and attention. Nat Rev Neurosci 12:509-523. CrossRef Medline

Henny P, Jones BE (2008) Projections from basal forebrain to prefrontal cortex comprise cholinergic, GABAergic and glutamatergic inputs to pyramidal cells or interneurons. Eur J Neurosci 27:654-670. CrossRef Medline

Herrero JL, Roberts MJ, Delicato LS, Gieselmann MA, Dayan P, Thiele A (2008) Acetylcholine contributes through muscarinic receptors to attentional modulation in V1. Nature 454:1110-1114. CrossRef Medline

Iijima K (1989) An immunocytochemical study on the GABA-ergic and serotonin-ergic neurons in rat locus ceruleus with special reference to possible existence of the masked indoleamine cells. Acta Histochem 87: 43-57. CrossRef Medline

Iijima K (1993) Chemocytoarchitecture of the rat locus ceruleus. Histol Histopathol 8:581-591. Medline

Iijima K, Ohtomo K (1988) Immunocytochemical study using a GABA antiserum for the demonstration of inhibitory neurons in the rat locus ceruleus. Am J Anat 181:43-52. CrossRef Medline

Iijima K, Sato M (1991) An immunocytochemical study using the PAP method for tyrosine hydroxylase and serotonin in alternate sections, and in situ hybridization to detect tryptophan hydroxylase mRNA in the rat's locus ceruleus. Acta Histochem 90:159-172. CrossRef Medline

Jones BE (1991) Noradrenergic locus coeruleus neurons: their distant connections and their relationship to neighboring (including cholinergic and GABAergic) neurons of the central gray and reticular formation. Prog Brain Res 88:15-30. CrossRef Medline

Lee SE, Jun SB, Lee HJ, Kim J, Lee SW, Im C, Shin HC, Chang JW, Kim SJ (2012) A flexible depth probe using liquid crystal polymer. IEEE Trans Biomed Eng 59:2085-2094. CrossRef Medline

Lee SH, Dan Y (2012) Neuromodulation of brain states. Neuron 76: 209-222. CrossRef Medline

López-Bendito G, Molnár Z (2003) Thalamocortical development: how are we going to get there? Nat Rev Neurosci 4:276-289. CrossRef Medline

Loughlin SE, Foote SL, Fallon JH (1982) Locus coeruleus projections to cortex: topography, morphology and collateralization. Brain Res Bull 9:287-294. CrossRef Medline

Luiten PG, Gaykema RP, Traber J, Spencer DG Jr (1987) Cortical projection patterns of magnocellular basal nucleus subdivisions as revealed by anterogradely transported Phaseolus vulgaris leucoagglutinin. Brain Res 413:229-250. CrossRef Medline

Mesulam MM, Mufson EJ, Levey AI, Wainer BH (1983) Cholinergic innervation of cortex by the basal forebrain: cytochemistry and cortical connections of the septal area, diagonal band nuclei, nucleus basalis (substantia innominata), and hypothalamus in the rhesus monkey. J Comp Neurol 214:170-197. CrossRef Medline

Metherate R, Cox CL, Ashe JH (1992) Cellular bases of neocortical activa- tion: modulation of neural oscillations by the nucleus basalis and endogenous acetylcholine. J Neurosci 12:4701-4711. Medline

Perez SE, Dar S, Ikonomovic MD, DeKosky ST, Mufson EJ (2007) Cholinergic forebrain degeneration in the APPswe/PS1DeltaE9 transgenic mouse. Neurobiol Dis 28:3-15. CrossRef Medline

Picciotto MR, Higley MJ, Mineur YS (2012) Acetylcholine as a neuromodulator: cholinergic signaling shapes nervous system function and behavior. Neuron 76:116-129. CrossRef Medline

Pinto L, Goard MJ, Estandian D, Xu M, Kwan AC, Lee SH, Harrison TC, Feng G, Dan Y (2013) Fast modulation of visual perception by basal forebrain cholinergic neurons. Nat Neurosci 16:1857-1863. CrossRef Medline

Poulet JF, Petersen CC (2008) Internal brain state regulates membrane potential synchrony in barrel cortex of behaving mice. Nature 454:881-885. CrossRef Medline

Rye DB, Wainer BH, Mesulam MM, Mufson EJ, Saper CB (1984) Cortical projections arising from the basal forebrain: a study of cholinergic and noncholinergic components employing combined retrograde tracing and immunohistochemical localization of choline acetyltransferase. Neuroscience 13:627-643. CrossRef Medline

Samuels ER, Szabadi E (2008) Functional neuroanatomy of the noradrenergic locus coeruleus: its roles in the regulation of arousal and autonomic function part I: principles of functional organisation. Curr Neuropharmacol 6:235-253. CrossRef Medline

Saper CB (1984) Organization of cerebral cortical afferent systems in the rat. II. Magnocellular basal nucleus. J Comp Neurol 222:313-342. CrossRef Medline

Sara SJ (2009) The locus coeruleus and noradrenergic modulation of cognition. Nat Rev Neurosci 10:211-223. CrossRef Medline

Sara SJ, Bouret S (2012) Orienting and reorienting: the locus coeruleus mediates cognition through arousal. Neuron 76:130-141. CrossRef Medline

Sarter M, Parikh V (2005) Choline transporters, cholinergic transmission and cognition. Nat Rev Neurosci 6:48-56. CrossRef Medline

Schwaber JS, Rogers WT, Satoh K, Fibiger HC (1987) Distribution and organization of cholinergic neurons in the rat forebrain demonstrated by computer-aided data acquisition and three-dimensional reconstruction. J Comp Neurol 263:309-325. CrossRef Medline

Schwarz LA, Miyamichi K, Gao XJ, Beier KT, Weissbourd B, DeLoach KE, Ren J, Ibanes S, Malenka RC, Kremer EJ, Luo L (2015) Viral-genetic tracing of the input-output organization of a central noradrenaline circuit. Nature 524:88-92. CrossRef Medline

Steindler DA, Trosko BK (1989) Two types of locus coeruleus neurons born on different embryonic days in the mouse. Anat Embryol 179:423-434. CrossRef Medline

Steinmetz PN, Roy A, Fitzgerald PJ, Hsiao SS, Johnson KO, Niebur E (2000) Attention modulates synchronized neuronal firing in primate somatosensory cortex. Nature 404:187-190. CrossRef Medline

Sturrock RR, Rao KA (1985) A quantitative histological study of neuronal loss from the locus coeruleus of ageing mice. Neuropathol Appl Neurobiol 11:55-60. CrossRef Medline

Swanson LW, Hartman BK (1975) The central adrenergic system. An immunofluorescence study of the location of cell bodies and their efferent connections in the rat utilizing dopamine-beta-hydroxylase as a marker. J Comp Neurol 163:467-505. CrossRef Medline

Waterhouse BD, Lin CS, Burne RA, Woodward DJ (1983) The distribution of neocortical projection neurons in the locus coeruleus. J Comp Neurol 217:418-431. CrossRef Medline

Woolf NJ (1991) Cholinergic systems in mammalian brain and spinal cord. Prog Neurobiol 37:475-524. CrossRef Medline

Woolf NJ (1996) Global and serial neurons form A hierarchically arranged interface proposed to underlie memory and cognition. Neuroscience 74: 625-651. CrossRef Medline

Woolf NJ, Eckenstein F, Butcher LL (1983) Cholinergic projections from the basal forebrain to the frontal cortex: a combined fluorescent tracer and immunohistochemical analysis in the rat. Neurosci Lett 40:93-98. CrossRef Medline 